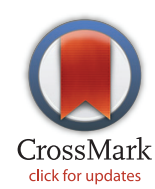

\section{G OPENACEESS}

Citation: Field KA, Johnson JS, Lilley TM, Reeder SM, Rogers EJ, Behr MJ, et al. (2015) The WhiteNose Syndrome Transcriptome: Activation of Antifungal Host Responses in Wing Tissue of Hibernating Little Brown Myotis. PLoS Pathog 11(10): e1005168. doi:10.1371/journal.ppat.1005168

Editor: Bruce S Klein, University of WisconsinMadison, UNITED STATES

Received: July 17, 2015

Accepted: August 25, 2015

Published: October 1, 2015

Copyright: ๑ 2015 Field et al. This is an open access article distributed under the terms of the Creative Commons Attribution License, which permits unrestricted use, distribution, and reproduction in any medium, provided the original author and source are credited.

Data Availability Statement: All RNA-Seq files are available from the SRA database (accession number SRP055976). All metagenome files are available from the MG-RAST database (project 11709).

Funding: This work was supported by the United States Fish and Wildlife Service grants F12AP01210 to DMR, F14AP00739 to DMR and KAF, and also the Woodtiger Fund to DMR and KAF and Bucknell University. The funders had no role in study design, data collection and analysis, decision to publish, or preparation of the manuscript.
RESEARCH ARTICLE

\section{The White-Nose Syndrome Transcriptome: Activation of Anti-fungal Host Responses in Wing Tissue of Hibernating Little Brown Myotis}

\author{
Kenneth A. Field ${ }^{1}$, Joseph S. Johnson ${ }^{1}$, Thomas M. Lilley ${ }^{1}$, Sophia M. Reeder ${ }^{1}$, Elizabeth \\ J. Rogers ${ }^{1}$, Melissa J. Behr ${ }^{2}$, DeeAnn M. Reeder ${ }^{1}$ \\ 1 Department of Biology, Bucknell University, Lewisburg, Pennsylvania, United States of America, \\ 2 Department of Pathobiological Sciences, School of Veterinary Medicine, University of Wisconsin-Madison, \\ Madison, Wisconsin, United States of America \\ *kfield@bucknell.edu
}

\section{Abstract}

White-nose syndrome (WNS) in North American bats is caused by an invasive cutaneous infection by the psychrophilic fungus Pseudogymnoascus destructans $(P d)$. We compared transcriptome-wide changes in gene expression using RNA-Seq on wing skin tissue from hibernating little brown myotis (Myotis lucifugus) with WNS to bats without $P d$ exposure. We found that WNS caused significant changes in gene expression in hibernating bats including pathways involved in inflammation, wound healing, and metabolism. Local acute inflammatory responses were initiated by fungal invasion. Gene expression was increased for inflammatory cytokines, including interleukins (IL) IL-1 $\beta$, IL-6, IL-17C, IL-20, IL-23A, IL24, and G-CSF and chemokines, such as Ccl2 and Ccl20. This pattern of gene expression changes demonstrates that WNS is accompanied by an innate anti-fungal host response similar to that caused by cutaneous Candida albicans infections. However, despite the apparent production of appropriate chemokines, immune cells such as neutrophils and $T$ cells do not appear to be recruited. We observed upregulation of acute inflammatory genes, including prostaglandin $\mathrm{G} / \mathrm{H}$ synthase 2 (cyclooxygenase-2), that generate eicosanoids and other nociception mediators. We also observed differences in Pd gene expression that suggest host-pathogen interactions that might determine WNS progression. We identified several classes of potential virulence factors that are expressed in Pd during WNS, including secreted proteases that may mediate tissue invasion. These results demonstrate that hibernation does not prevent a local inflammatory response to $P d$ infection but that recruitment of leukocytes to the site of infection does not occur. The putative virulence factors may provide novel targets for treatment or prevention of WNS. These observations support a dual role for inflammation during WNS; inflammatory responses provide protection but excessive inflammation may contribute to mortality, either by affecting torpor behavior or causing damage upon emergence in the spring. 
Competing Interests: The authors have declared that no competing interests exist.

\section{Author Summary}

White-nose syndrome is the most devastating epizootic wildlife disease of mammals in history, having killed millions of hibernating bats in North America since 2007. We have used next-generation RNA sequencing to provide a survey of the gene expression changes that accompany this disease in the skin of bats infected with the causative fungus. We identified possible new mechanisms that may either provide protection or contribute to mortality, including inflammatory immune responses. Contrary to expectations that hibernation represents a period of dormancy, we found that gene expression pathways were responsive to the environment. We also examined which genes were expressed in the pathogen and identified several classes of genes that could contribute to the virulence of this disease. Gene expression changes in the host were associated with local inflammation despite the fact that the bats were hibernating. However, we found that hibernating bats with white-nose syndrome lack some of the responses known to defend other mammals from fungal infection. We propose that bats could be protected from white-nose syndrome if these responses could be established prior to hibernation or if treatments could block the virulence factors expressed by the pathogen.

\section{Introduction}

White-nose syndrome (WNS) is an epizootic disease that has killed millions of bats in North America $[1,2]$. WNS is caused by the psychrophile Pseudogymnoascus destructans (Pd) (formerly Geomyces destructans), an ascomycete fungal pathogen [3-5] that affects bats during hibernation. $P d$ grows at temperatures between 2 and $18^{\circ} \mathrm{C}$ and can infect bats while they hibernate $[4,6] . P d$ is invasive and damages the cutaneous tissues of bats, including the wing [7], forming characteristic cupping erosions that are diagnostic of $P d$ infection [8]. Mortality rates due to WNS vary by species. In the little brown myotis, Myotis lucifugus, the mortality rate is up to $91 \%$ in affected caves $[9,10]$ whereas WNS resistance has been reported in the big brown bat, Eptesicus fuscus [11]. Bats in Europe are exposed to endemic $P d$, but do not exhibit WNS mortality and appear to be resistant to the disease [12], despite cutaneous invasion by $P d$ [13].

Cutaneous infection by $P d$ causes some species of bats to arouse more frequently from torpor $[5,14,15]$. Although hibernating mammals spend less than $1 \%$ of their time euthermic [16], they use up to $90 \%$ of their stored energy during these periods [17, 18]. Because each arousal in little brown myotis utilizes an estimated $108 \mathrm{mg}$ of stored fat [18], the increase in arousal frequency caused by WNS explains $58 \%$ of the morbidity rate associated with $P d$ infection [14]. Other factors that are also associated WNS pathology include effects of $P d$ infection on the integrity of wing tissue $[7,19]$, electrolyte balance and hydration $[7,20,21]$, chronic respiratory acidosis [22], oxidative stress [23], and immune function [24]. The relative importance of each of these mechanisms in causing death in WNS is not clear, and the most likely model that has emerged is a multi-stage progression of WNS with contributions of several of these factors [22]. Differences in susceptibility to WNS between species in North America may be explained in part by different responses to $P d$ infection such as changes in thermoregulatory behavior. Understanding host responses to $P d$ infection may provide insight that could be useful for improving survival of affected species.

Cutaneous fungal infections in mammals are first recognized by components of the innate immune system, including C-type lectin receptors and Toll-like receptors [25]. Conserved components of the fungal cell wall activate pattern recognition receptors on phagocytes such as 
neutrophils, macrophages, and dendritic cells, and on epithelial cells [26]. Activation of these cells can lead to induction of the inflammasome, the production of inflammatory cytokines, and generation of reactive oxygen species that can mediate fungal cell killing [25]. The importance of the innate immune response to the initial recognition of fungal infections is demonstrated by the observation that deficiencies in these signaling pathways can lead to chronic fungal infections in humans [27, 28]. In the absence of invasion, colonization by commensal fungi can be maintained through tolerance mechanisms mediated by interactions with dendritic cells and epithelial cells in the skin [29]. Local activation of innate immune pathways can slow the growth of invasive pathogenic fungi and promote tolerance, possibly leading to a commensal relationship with the fungus [30], but is not usually sufficient to clear infections. Clearance of infections typically requires $\mathrm{T}$ helper (Th) cells, as demonstrated by the susceptibility of patients with acquired immune deficiency syndrome, immunosuppressant therapy, or chemotherapy to fungal infections [31]. These $\mathrm{T}$ cell responses can be mediated by Th17 cells [32, 33] or, in some cases, Th1 cells [34], with Th2 responses typically associated with greater susceptibility [35]. Th17 responses can contribute to clearance of invasive fungal infections through the actions of IL-17A and IL-22 [36] and the further recruitment and activation of neutrophils [37]. These $\mathrm{T}$ cell subsets have not been well characterized in bats, but those $\mathrm{T}$-cell mediated immune mechanisms that have been studied appear to be conserved between bats and other mammals [38-41].

Fungal infections in animals are typically life-threatening only upon suppression of adaptive immune responses in the host, such as when chytrid fungus (Batrachochytrium dendrobatidis) blocks lymphocyte-mediated inflammatory responses [42]. Hibernation produces a natural suppression of some immune responses in mammal species where it has been studied. During hibernation, when the conservation of energy is critical, certain immunological mechanisms are downregulated while others remain unaffected [43-51]. Changes during hibernation can include depressed antibody responses [44,52], decreased ability of $\mathrm{T}$ and $\mathrm{B}$ lymphocytes to proliferate in response to challenge [53,54], and reduced complement activity [47]. Hibernation does not affect all immune responses equally, as shown in thirteen-lined ground squirrels (Ictidomys tridecemlineatus) that have a suppressed T-independent antibody response but are capable of mounting a T cell-dependent response during hibernation [44]. Studies of transcriptome-wide changes during hibernation in squirrels [55-59] have shown expression changes in genes involved in metabolism, oxidative stress, protein folding, ischemia/hypoxia, and other processes, but these studies were not examining an active immune response. Hibernation is also known to affect the distribution of leukocytes [45, 60] and platelets [61]. However, we have an incomplete understanding of how hibernation affects the suppression, or subsequent recovery, of immune responses [43], or how immune physiology in bats during hibernation may differ from that of rodents.

The cost of immune suppression during torpor is presumably outweighed by the benefits of energy conservation because most pathogens are not capable of proliferating at the low body temperatures of hibernating animals. However, the psychrophilic nature of $P d$ allows it to infect bats within hibernacula [2, 4]. The brief euthermic bouts of hibernating bats are shorter than most other hibernating mammalian species $[14,62]$ and it may not be possible for a bat naïve to a pathogen to mount a primary immune response in the few hours that it is euthermic throughout the hibernation season. We have observed antibody responses to $P d$ in bats, but these responses are strongest in active bats exposed to $P d$ after emergence from hibernation [63]. Therefore, hibernating bats may keep pathogens in check by relying on hypothermia, innate immune responses, and/or memory immune responses. The psychrophilic nature of $P d$ overcomes the first of these barriers to infection and the difficulty in fighting fungal pathogens 
with innate mechanisms alone may allow $P d$ to proliferate and invade the cutaneous tissues of bats.

The WNS panzootic has created an urgent need to understand if North American bat populations can persist in the presence of the fungal pathogen $[1,10]$. Understanding the complete array of host responses mounted by bats afflicted with WNS may help illuminate sources of variation in survival within and among bat species. To determine which host responses are activated by $P d$ infection, we measured transcriptome-wide gene expression levels in bat wing tissue from hibernating bats affected by WNS. Gene expression was compared to bats that were hibernated in captivity in the absence of $P d$ exposure. We hypothesized that $P d$ infection would cause changes in gene expression that would reveal physiological responses during WNS that might be either protective or pathological. By using next-generation RNA sequencing to examine transcriptome-wide gene expression changes we expected to discover consistent patterns of host responses that occur in $P d$-infected tissues. Combined with changes in gene expression within the $P d$ pathogen, these results have provided a survey of the host and pathogen interactions occurring during WNS.

\section{Results}

\section{Gene Expression Changes Revealed by Next Generation RNA Sequencing}

To determine the host response mounted by little brown myotis to $P d$ during hibernation, we measured changes in gene expression at the whole transcriptome level. Wing tissue samples were obtained from hibernating little brown myotis with no known exposure to $P d$ and bats exhibiting physical signs of WNS, as shown in Table 1. Histopathology [8] and quantitative PCR (qPCR) for $P d[64$ ] were used to confirm the WNS status of each bat (Table 1). Cupping erosions diagnostic of WNS were found on all 6 bats captured in Kentucky, but on none of the 5 bats from states negative for WNS at the time of capture. Low levels of neutrophilic inflammation were found in all 11 wing samples (Table 1; Infl), although this inflammation was not associated with sites of $P d$ infection. All 6 WNS-affected bats tested positive for $P d$ by qPCR, although the fungal load measured on wing swabs (Table 1; qPCR) did not correlate with the number of cupping erosions found by histology (Table 1; WNS). As previously shown [5, 14, 15], WNS-affected bats had significantly lower body condition (Table 1; SMI; $\mathrm{p}=0.017$, $\mathrm{t}=2.9255, \mathrm{df}=9$ ).

Next generation RNA sequencing (RNA-Seq) was performed using poly-A selected RNA isolated from each RNAlater-preserved wing tissue sample ( $\mathrm{S} 1 \mathrm{Table}$ ). Using expression levels of $P d$-derived transcripts, we confirmed that all 6 WNS-affected bats had abundant expression of $P d$ genes. The $P d$-derived transcripts were not present at significant levels in any of the 5 samples from unaffected bats ( $\mathrm{S} 2 \mathrm{Table} ; \mathrm{p}=2.2 \times 10^{-6}, \mathrm{t}=21.5, \mathrm{df}=5.33$ ), including the MN090 sample that had tested positive for $P d$ by qPCR in one of the two replicates (Table 1 ). Because high levels of differential expression of $P d$ transcripts would make it more difficult to detect significant changes in host gene expression, the assembly was filtered [65] to remove $P d$-derived sequences. Comparison of the filtered assembly with the original revealed that removing the $P d$ sequences did not significantly decrease the completeness of the assembly ( 33 Table) as determined by BUSCO [66]. This filtered assembly (S1 Dataset) was used to calculate differential expression in host genes between the unaffected and WNS-affected samples.

We compared host gene expression across all samples (S2 Dataset) using DESeq2 [67] to identify transcript clusters that were expressed at a minimum of 2-fold difference and significant at a false discovery rate (FDR) of 0.05 (S1 Fig). We found 1804 transcript clusters that were expressed at higher levels, and 1925 transcript clusters expressed at lower levels, in WNS- 
Table 1. Samples used for next generation RNA sequencing.

\begin{tabular}{|c|c|c|c|c|c|c|c|c|c|}
\hline \multirow[t]{2}{*}{ Sample } & \multirow[t]{2}{*}{ Location } & \multirow[t]{2}{*}{ Date Captured } & \multirow[t]{2}{*}{ Date Sampled } & \multirow[t]{2}{*}{ Sex } & \multirow[t]{2}{*}{ Mass } & \multirow[t]{2}{*}{ SMI ${ }^{1}$} & \multirow[t]{2}{*}{$P d$ Load by qPCR ${ }^{2}$} & \multicolumn{2}{|c|}{ Histology } \\
\hline & & & & & & & & WNS $^{3}$ & $\left.\operatorname{lnfl}\right|^{4}$ \\
\hline MI011 & Mine in Dickinson Co, MI & 5-Nov-2011 & 22-Mar-2012 & $M$ & 6.70 & 6.69 & Negative & 0 & 9 \\
\hline MN064 & Mine in Saint Louis Co, MN & 16-Nov-2011 & 22-Mar-2012 & $\mathrm{F}$ & 7.41 & 7.15 & Negative & 0 & 2 \\
\hline MN075 & Mine in Saint Louis Co, MN & 16-Nov-2011 & 22-Mar-2012 & $\mathrm{F}$ & 7.47 & 7.68 & Negative & 0 & 50 \\
\hline MN090 & Mine in Saint Louis Co, MN & 16-Nov-2011 & 22-Mar-2012 & $M$ & 7.66 & 7.51 & Neg/Pos? & 0 & 13 \\
\hline IL114 & Mine in LaSalle Co, IL & 17-Nov-2011 & 22-Mar-2012 & $\mathrm{F}$ & 7.13 & 7.40 & Negative & 0 & 2 \\
\hline KY06 & Cave 1 in Breckinridge Co, $\mathrm{KY}$ & 12-Mar-2014 & 12-Mar-2014 & $\mathrm{F}$ & 6.04 & 6.17 & 120000 & 352 & 25 \\
\hline KY07 & Cave 1 in Breckinridge $\mathrm{Co}, \mathrm{KY}$ & 12-Mar-2014 & 12-Mar-2014 & $\mathrm{F}$ & 6.90 & 6.89 & 13000 & 438 & 57 \\
\hline KY11 & Cave 1 in Breckinridge $\mathrm{Co}, \mathrm{KY}$ & 12-Mar-2014 & 12-Mar-2014 & M & 5.47 & 6.12 & 169000 & 288 & 3 \\
\hline KY19 & Cave 2 in Breckinridge Co, $\mathrm{KY}$ & 12-Mar-2014 & 12-Mar-2014 & $M$ & 6.28 & 6.93 & 64000 & 117 & 9 \\
\hline KY23 & Cave 2 in Breckinridge Co, $\mathrm{KY}$ & 12-Mar-2014 & 12-Mar-2014 & $\mathrm{F}$ & 6.58 & 6.89 & 21000 & 234 & 10 \\
\hline KY39 & Cave in Jackson Co, $\mathrm{KY}$ & 13-Mar-2014 & 13-Mar-2014 & $\mathrm{M}$ & 6.28 & 6.69 & 120000 & 197 & 10 \\
\hline
\end{tabular}

${ }^{1}$ Scaled mass index: $(\text { mass(in g) })^{*}\left(38.01 /(\text { forearm length(in mm) })^{\wedge} 1.406\right.$

${ }^{2}$ Wing swabs from MI, MN, and IL were measured in duplicate and determined to be positive for $P d$ if the cycle-threshold was less than 40 . Samples from KY were quantified in $P d$ genomic equivalents relative to swabs spiked with $10000 P d$ conidia.

${ }^{3}$ Cupping erosions characteristic of WNS per roll of wing tissue.

${ }^{4}$ Foci of neutrophilic inflammation per roll of wing tissue.

doi:10.1371/journal.ppat.1005168.t001

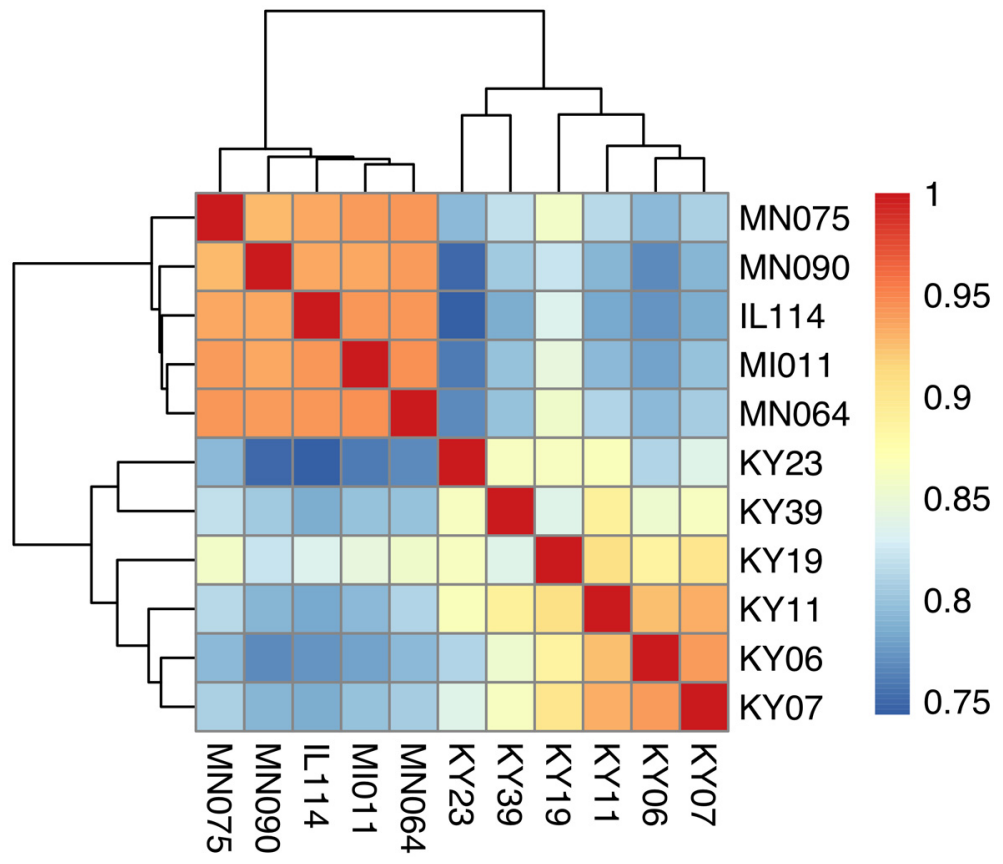

Fig 1. Hierarchical clustering of gene expression in WNS-affected and unaffected bats. Hierarchical clustering of differentially expressed genes using Pearson correlation complete-linkage clustering. Scale shows Pearson correlation coefficient.

doi:10.1371/journal.ppat.1005168.g001 
affected bat tissues ( $\$ 4$ Table). Hierarchical clustering (Fig 1) revealed that expression of these transcripts from all 5 bats without WNS was similar to each other. Gene expression in wing tissue from WNS-affected bats was different from unaffected bats and more similar to each other, as predicted. The normalized expression levels of the 3729 identified transcript clusters differentially expressed are listed in S4 Table.

Differential expression of individual gene isoforms was further analyzed using EBSeq [68], an empirical Bayesian approach to modeling gene expression. For each transcript cluster identified as differentially expressed by DESeq2, we used EBSeq to determine if any of the individual transcripts were differentially expressed at a posterior probability greater than 0.99 (S4 Table). Of the 3729 differentially expressed transcript clusters identified by DESeq2, EBSeq identified at least one differentially expressed transcript for 1427 (38\% of total, $43 \%$ of upregulated genes and $33 \%$ of downregulated genes). These results indicate that differences in gene expression are likely due to alternative splicing or other isoform differences for many of the differentially expressed genes.

To annotate the functions of these genes and identify those likely to be involved with host responses to $P d$ infection, we used the Trinotate pipeline. BLAST was used to identify 1365 upregulated transcripts and 325 downregulated transcripts in WNS-affected tissues with significant homology to known genes from vertebrates in the Swissprot database. Of the 2295 remaining transcripts, 13 were mapped to genes from non-vertebrates in the Swissprot database, presumably due to environmental contamination or incomplete removal of $P d$ transcript sequences. Of the 2842 trinity transcript clusters without a BLASTx match in Swissprot, 2731 $(96 \%)$ were found to align to sequences (e-value $<0.0001$ ) in the little brown myotis genome. Of the aligned transcripts, 204 (7.4\%) were found to correspond to previously identified noncoding RNA sequences. Of the 111 transcript clusters without a transcript that aligned to the little brown myotis genome or Swissprot, BLAST was used to align their transcripts to the UniRef90 database. We found that 7 genes aligned to vertebrate homologs, 9 aligned to fungal homologs, and 15 aligned to other metagenomic sequences. We were unable to identify homologous sequences for any transcripts from $80(2.1 \%)$ of the transcript clusters that were differentially expressed.

Expression levels for the Swissprot-identified transcript clusters with the 100 lowest adjusted $\mathrm{p}$ values are shown in Fig 2 (see 44 Table for all results). Some of the differentially expressed genes with putative functions that were predicted to associate with host responses to a fungal pathogen are listed in Table 2. WNS caused dramatic changes in expression of genes involved in inflammation, immune responses, wound healing, metabolism, and oxidative stress, even though the bats were hibernating during the $P d$ infection. Most of these genes were upregulated in WNS-affected tissues, while a much smaller number of identified genes with putative functions in these categories were downregulated (Tables 2 and S4).

To determine if all 6 little brown myotis with WNS exhibit similar changes in gene expression, we performed clustering analysis of the differentially expressed transcripts (Fig 1). To confirm the significance of these patterns of gene expression, bootstrap analysis of clustering was performed [69]. The clustering of the unaffected samples together and the clustering of the WNS-affected samples together was verified with a confidence of $99 \%$ (Fig 3A). Principal component analysis was performed to better understand the relationships between the transcripts expressed in the 11 samples (Fig 3B). All 5 samples from unaffected bats were very similar based on the first three principal components identified, which account for $71 \%$ of the variance in these transcripts. The WNS-affected bat samples have more diverse gene expression (S5 Table) and PC1 (accounting for $44 \%$ of the variance) differentiates all 6 from the unaffected bat samples. The genes represented by PC1 include those that are more highly expressed in unaffected than WNS-affected wing tissue (Fig 2). PC2 (17\% of the variance) and PC3 (10\% of 


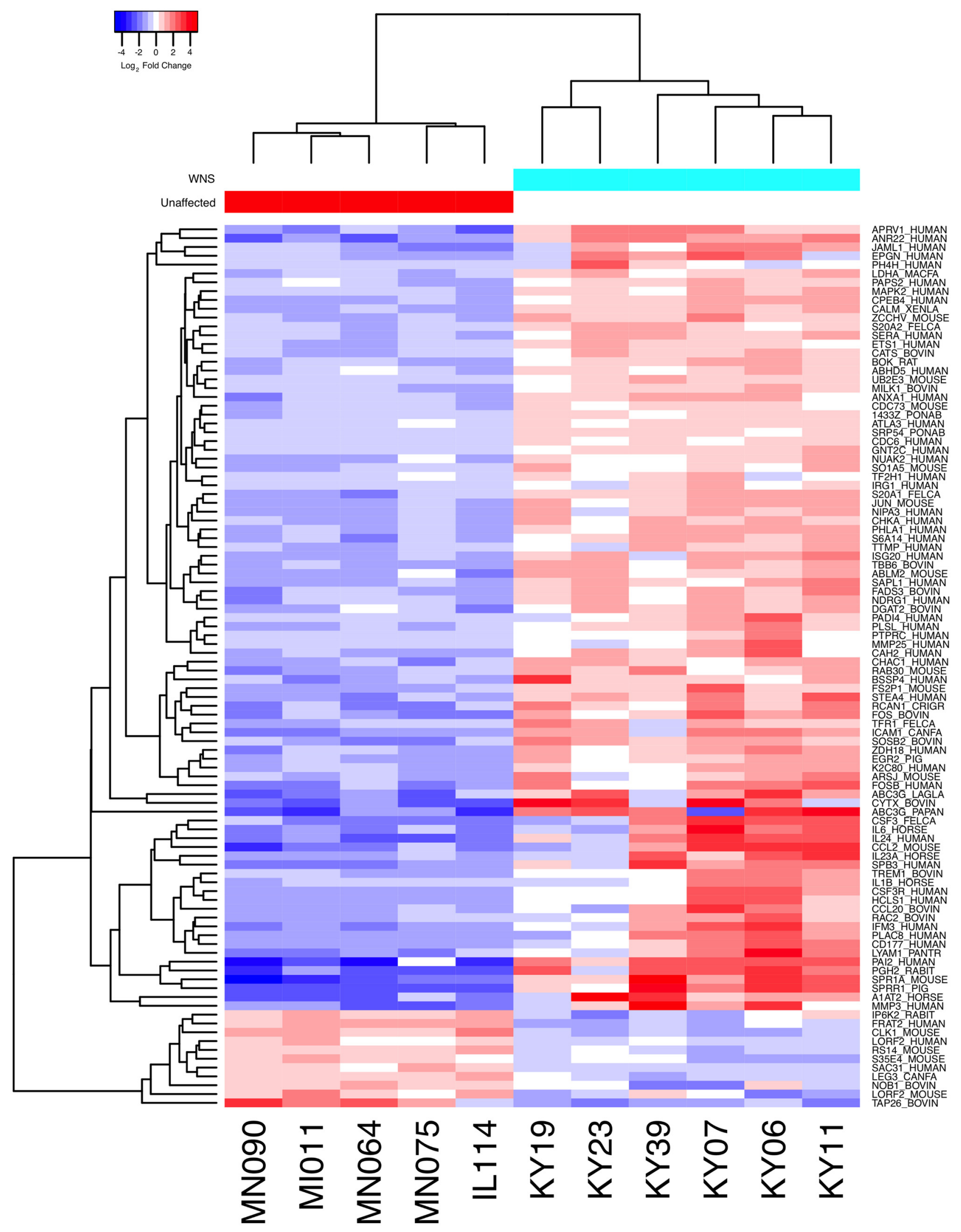

Fig 2. Global transcriptional analysis of WNS-affected and unaffected bats by RNA-Seq. Centered $\log _{2}$ fold changes are shown for the 100 most significant differentially expressed identified genes. Adjusted $p$ values ranged from $3.3 \times 10^{-5}$ to $2.8 \times 10^{-18}$. The heatmap of TMM-normalized FPKM expression 
estimates is centered and $\log _{2}$ scaled from a minimum of -4.8 to a maximum of 4.8. Transcripts were identified by BLAST alignment to the SwissProt database.

doi:10.1371/journal.ppat.1005168.g002

Table 2. Selected genes differentially expressed in WNS-affected tissues.

\begin{tabular}{|c|c|c|c|c|c|c|}
\hline Gene $^{1}$ & Full Name & $\mathrm{FC}^{2}$ & pvalue $^{3}$ & $\operatorname{padj}^{4}$ & EB FC ${ }^{5}$ & PPEE $^{6}$ \\
\hline \multicolumn{7}{|c|}{ Inflammation } \\
\hline IL23A & Interleukin-23 subunit alpha & 32.6 & 4.8E-09 & 2.0E-06 & 33.6 & $1.9 \mathrm{E}-08$ \\
\hline PGH2 & Prostaglandin G/H synthase 2 (Cyclooxygenase-2) & 30.5 & $1.2 \mathrm{E}-14$ & 2.1E-11 & 42.3 & $3.2 \mathrm{E}-12$ \\
\hline IL6 & Interleukin-6 & 30.3 & 1.1E-10 & 9.9E-08 & 50.9 & $5.2 \mathrm{E}-0 \mathrm{~S}$ \\
\hline MMP25 & Matrix metalloproteinase-25 & 25.7 & 5.1E-09 & 2.0E-06 & 25.5 & 5.7E-06 \\
\hline CSF3R & Granulocyte colony-stimulating factor receptor & 23.7 & 1.7E-09 & 9.1E-07 & 31.3 & $6.9 \mathrm{E}-08$ \\
\hline CCL20 & C-C motif chemokine 20 & 22.0 & 1.4E-07 & 3.0E-05 & 21.1 & 3.3E-06 \\
\hline IL20 & Interleukin-20 & 20.2 & 2.9E-07 & 5.3E-05 & 21.5 & $1.5 \mathrm{E}-06$ \\
\hline CSF3 & Granulocyte colony-stimulating factor & 19.1 & $6.8 \mathrm{E}-08$ & 1.8E-05 & 44.4 & 2.3E-07 \\
\hline IL1B & Interleukin-1 beta & 17.7 & 5.6E-08 & $1.5 \mathrm{E}-05$ & 13.6 & $6.6 \mathrm{E}-06$ \\
\hline IL1A & Interleukin-1 alpha & 15.4 & 4.5E-05 & 2.1E-03 & 11.4 & 3.1E-04 \\
\hline PA21 & Phospholipase A2 & 13.8 & 3.7E-04 & $9.1 \mathrm{E}-03$ & NA & $\mathrm{N} A$ \\
\hline CCL2 & C-C motif chemokine 2 & 12.3 & $6.5 \mathrm{E}-06$ & 5.3E-04 & 16.7 & 2.7E-05 \\
\hline IL17C & Interleukin-17C & 10.3 & $6.5 \mathrm{E}-07$ & 9.6E-05 & 12.7 & $3.0 \mathrm{E}-05$ \\
\hline IL19 & Interleukin-19 & 9.0 & 1.4E-04 & 4.7E-03 & NA & $\mathrm{N} A$ \\
\hline IL24 & Interleukin-24 & 7.6 & 3.4E-08 & $1.0 \mathrm{E}-05$ & 18.9 & $1.3 \mathrm{E}-05$ \\
\hline NCF2 & Neutrophil cytosol factor 2 & 5.7 & 9.9E-05 & $3.8 \mathrm{E}-03$ & 5.0 & $5.6 \mathrm{E}-04$ \\
\hline PG12A & Group XIIA secretory phospholipase A2 & 2.7 & $9.4 \mathrm{E}-07$ & 1.3E-04 & 3.1 & 5.7E-07 \\
\hline S10AC & Protein S100-A12 & 2.3 & 9.0E-04 & 1.7E-02 & NA & $\mathrm{N} A$ \\
\hline \multicolumn{7}{|c|}{ Other Immune Genes } \\
\hline $\mathrm{ABC} 3 \mathrm{G}$ & DNA dC->dU-editing enzyme APOBEC-3G & 32.4 & 3.9E-12 & 4.7E-09 & 54.2 & $4.1 \mathrm{E}-10$ \\
\hline LIRA6 & Leukocyte immunoglobulin-like receptor subfamily A member 6 & 23.1 & $1.5 \mathrm{E}-05$ & 9.5E-04 & NA & $\mathrm{N} A$ \\
\hline HPT & Haptoglobin & 18.9 & 3.3E-05 & 1.7E-03 & 72.2 & $3.9 \mathrm{E}-0 \varepsilon$ \\
\hline CD3G & T-cell surface glycoprotein CD3 gamma chain & 14.8 & $6.7 \mathrm{E}-06$ & 5.5E-04 & NA & $\mathrm{N} A$ \\
\hline CLC4D & C-type lectin domain family 4 member $\mathrm{D}$ & 12.5 & 7.0E-05 & 2.9E-03 & NA & $\mathrm{N} A$ \\
\hline PTPRC & Receptor-type tyrosine-protein phosphatase C & 12.3 & 1.4E-07 & 3.1E-05 & 16.0 & $1.1 \mathrm{E}-04$ \\
\hline CLC4E & C-type lectin domain family 4 member $\mathrm{E}$ & 12.3 & 3.6E-07 & $6.0 \mathrm{E}-05$ & NA & $\mathrm{N} A$ \\
\hline CLC7A & C-type lectin domain family 7 member $A$ & 10.9 & 5.4E-07 & 8.3E-05 & NA & $\mathrm{N} A$ \\
\hline $\mathrm{CO} 3$ & Complement C3 & 10.1 & 2.7E-03 & 3.4E-02 & 64.9 & 8.0E-08 \\
\hline TLR9 & Toll-like receptor 9 & 8.9 & 1.4E-06 & 1.7E-04 & 6.2 & $2.5 \mathrm{E}-05$ \\
\hline S10A3 & Protein S100-A3 & 8.4 & 4.8E-04 & 1.1E-02 & NA & $\mathrm{N} A$ \\
\hline CLC6A & C-type lectin domain family 6 member $A$ & 7.0 & $1.5 \mathrm{E}-04$ & 5.0E-03 & 7.0 & $3.9 \mathrm{E}-03$ \\
\hline CLC1A & C-type lectin domain family 1 member $A$ & 6.5 & 2.4E-06 & 2.6E-04 & NA & $\mathrm{N} A$ \\
\hline D103A & Beta-defensin $103 \mathrm{~A}$ & 6.1 & 5.4E-06 & 4.7E-04 & 6.3 & $3.2 \mathrm{E}-03$ \\
\hline CLC5A & C-type lectin domain family 5 member $A$ & 5.1 & 3.3E-04 & 8.3E-03 & NA & $\mathrm{NA}$ \\
\hline BIRC3 & Baculoviral IAP repeat-containing protein 3 & 3.4 & 7.9E-05 & 3.2E-03 & 4.6 & 3.3E-04 \\
\hline UNG & Uracil-DNA glycosylase & -3.8 & 1.0E-03 & 1.8E-02 & NA & $\mathrm{N} A$ \\
\hline LEG3 & Galectin-3 & -3.4 & 5.0E-08 & 1.4E-05 & 0.28 & $1.0 \mathrm{E}-10$ \\
\hline \multicolumn{7}{|c|}{ Wound Healing } \\
\hline SPRR1 & Cornifin & 184.6 & $4.1 \mathrm{E}-17$ & $1.0 \mathrm{E}-13$ & 66.4 & $<1 \mathrm{E}-16$ \\
\hline LCE3C & Late cornified envelope protein $3 \mathrm{C}$ & 17.5 & 2.1E-09 & 1.1E-06 & 15.0 & $6.2 \mathrm{E}-05$ \\
\hline FIBB & Fibrinogen beta chain & 15.9 & 1.8E-04 & $5.6 \mathrm{E}-03$ & 67.2 & $5.2 \mathrm{E}-0 \varepsilon$ \\
\hline
\end{tabular}


Table 2. (Continued)

\begin{tabular}{|c|c|c|c|c|c|c|}
\hline Gene $^{1}$ & Full Name & $\mathrm{FC}^{2}$ & pvalue $^{3}$ & $\operatorname{padj}^{4}$ & EB FC ${ }^{5}$ & PPEE $^{6}$ \\
\hline FIBA & Fibrinogen alpha chain & 12.4 & $1.1 \mathrm{E}-03$ & 1.9E-02 & 88.1 & $1.6 \mathrm{E}-08$ \\
\hline ARGI1 & Arginase-1 & 11.9 & 4.8E-04 & 1.1E-02 & NA & NA \\
\hline FIBG & Fibrinogen gamma chain & 11.8 & 1.4E-03 & 2.2E-02 & 48.9 & 1.6E-07 \\
\hline EPGN & Epigen & 10.3 & 2.0E-09 & 1.1E-06 & 13.1 & 7.3E-06 \\
\hline EREG & Proepiregulin & 8.8 & $6.9 \mathrm{E}-07$ & 1.0E-04 & 10.7 & 4.8E-04 \\
\hline KLK6 & Kallikrein-6 & 8.1 & 3.4E-07 & 5.9E-05 & 9.1 & 4.2E-04 \\
\hline $\mathrm{K} 1 \mathrm{C} 17$ & Keratin, type I cytoskeletal 17 & 5.9 & 1.3E-05 & 8.7E-04 & 6.6 & 3.7E-03 \\
\hline P63 & Tumor protein 63 & 3.1 & 2.0E-05 & 1.2E-03 & 16.9 & $9.8 \mathrm{E}-05$ \\
\hline \multicolumn{7}{|c|}{ Metabolism } \\
\hline PLAC8 & Placenta-specific gene 8 protein & 37.0 & 1.5E-09 & 8.4E-07 & 25.9 & 1.3E-05 \\
\hline LIPP & Pancreatic triacylglycerol lipase & 22.3 & 1.0E-06 & 1.3E-04 & 19.4 & 2.7E-06 \\
\hline ANGL3 & Angiopoietin-related protein 3 & 17.2 & $1.5 \mathrm{E}-04$ & 4.9E-03 & NA & NA \\
\hline APOC4 & Apolipoprotein C-IV & 16.1 & 7.9E-05 & 3.2E-03 & NA & NA \\
\hline APOC3 & Apolipoprotein C-III & 15.8 & $1.8 \mathrm{E}-04$ & 5.5E-03 & 42.5 & 8.7E-07 \\
\hline APOC2 & Apolipoprotein C-II & 14.5 & 3.7E-04 & $9.2 \mathrm{E}-03$ & 45.0 & $6.8 \mathrm{E}-07$ \\
\hline FFAR2 & Free fatty acid receptor 2 & 7.7 & 1.8E-05 & 1.1E-03 & 7.3 & $9.1 \mathrm{E}-04$ \\
\hline HCAR2 & Hydroxycarboxylic acid receptor 2 & 4.0 & 6.9E-04 & 1.4E-02 & NA & NA \\
\hline IP6K2 & Inositol hexakisphosphate kinase 2 & -5.0 & 3.8E-06 & 3.6E-04 & 0.19 & 2.2E-03 \\
\hline ACACA & Acetyl-CoA carboxylase 1 & -4.2 & 1.1E-03 & 1.9E-02 & 0.16 & 6.7E-03 \\
\hline \multicolumn{7}{|c|}{ Other Oxidative Stress } \\
\hline MMP3 & Stromelysin-1 & 34.0 & $3.4 \mathrm{E}-10$ & 2.5E-07 & 57.7 & $6.6 \mathrm{E}-08$ \\
\hline PERT & Thyroid peroxidase & 3.7 & 2.7E-03 & 3.4E-02 & NA & NA \\
\hline PRDX2 & Peroxiredoxin-2 & 3.6 & 1.1E-05 & 7.8E-04 & NA & NA \\
\hline HMOX1 & Heme oxygenase 1 & 3.0 & 5.4E-04 & 1.2E-02 & 8.2 & 1.7E-03 \\
\hline
\end{tabular}

${ }^{1}$ BLAST hit with the lowest E-value in the Swissprot database. Only genes with $\mathrm{E}<1 \mathrm{E}-05$ were considered.

${ }^{2}$ Fold change in gene expression of the WNS-affected samples compared to the unaffected samples as determined by DESeq2. Negative values indicate higher expression in the unaffected samples.

${ }^{3}$ Probability of differential expression determined by DESeq2.

${ }^{4}$ Adjusted probability of differential expression after Benjamini-Hochberg FDR correction.

${ }^{5}$ Posterior probability fold change in EBSeq-estimated expression of each transcript in WNS-affected tissues over unaffected tissues. NA indicates that no isoform for that gene was differentially expressed at an FDR $<0.001$

${ }^{6}$ Posterior probability estimate by EBSeq that the isoform is differentially expressed.

doi:10.1371/journal.ppat.1005168.t002

the variance) distinguish the KY19, KY23, and KY39 samples from the other two WNSaffected samples and from the unaffected samples. The rotation values of principal component analysis (S5 Table) reveal that inflammatory genes made the greatest contribution to PC2. Clustering analysis revealed diverse host responses among the bats infected with $P d$.

\section{Metabolic and Inflammatory Immune Pathways Associated with WNS}

We next examined the functional pathways that were most affected in little brown myotis infected with $P d$. For this gene ontology analysis, DESeq2 results on transcript isoforms were used with a higher FDR threshold of 0.1, as is typical for this type of analysis. From WNSaffected bat tissue, 3104 upregulated transcripts were aligned with BLAST to the human Uniprot database. Homologs for these transcripts were identified and a list of 1937 unique Ensembl IDs associated with upregulated genes was generated (S6 Table). GOrilla [70] was used to 


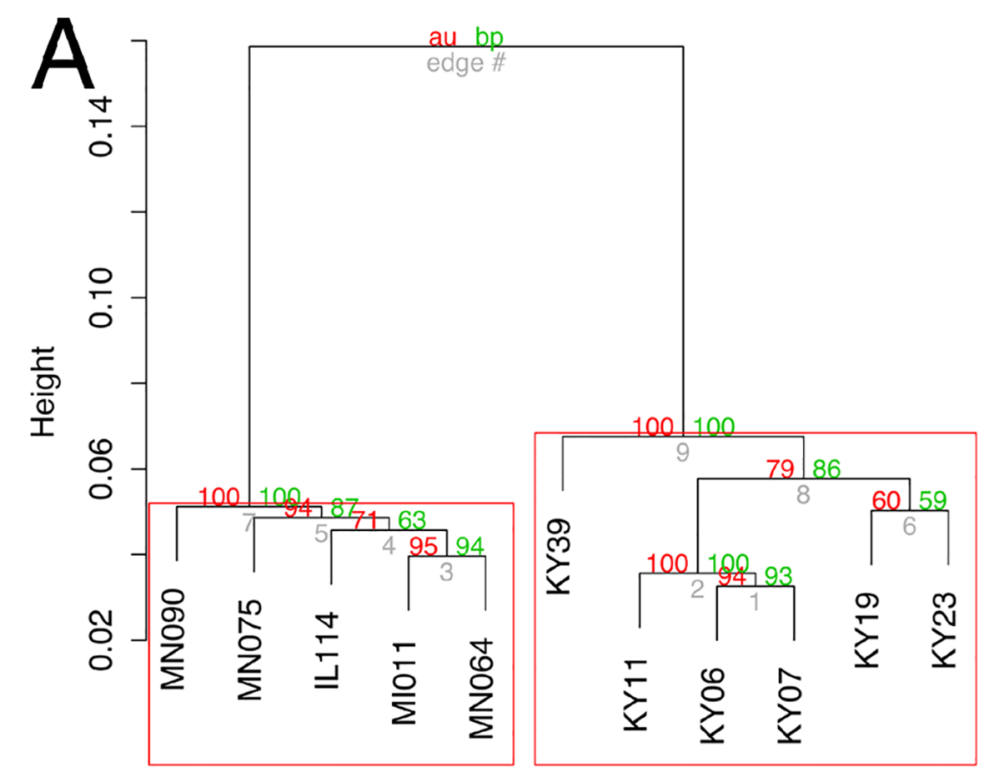

$\mathrm{B}$

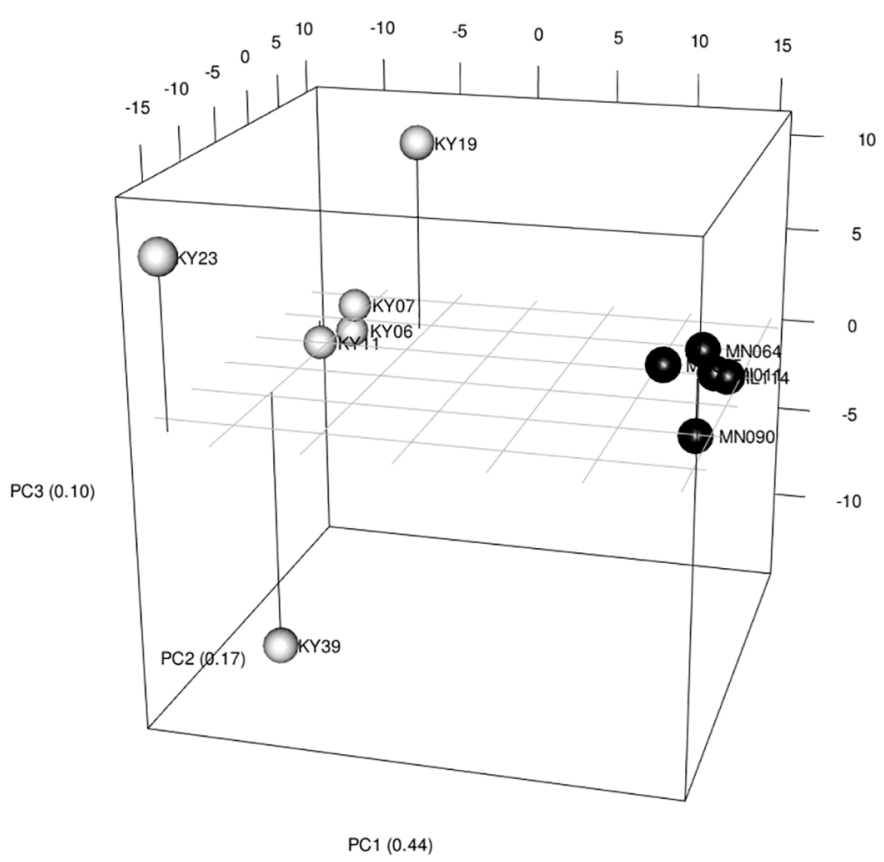

Fig 3. Clustering of gene expression patterns. (A) Bootstrap analysis of regularized-log transformed counts to assign confidence levels to sample clustering. Red values are approximately unbiased $p$ values and green values are bootstrap probabilities. Red boxes indicate clusters supported at a confidence level of $99 \%$. (B) Principal component analysis of regularized-log transformed counts of differentially expressed genes. Black spheres represent unaffected bats and white spheres represent WNS-affected bats.

doi:10.1371/journal.ppat.1005168.g003

determine significantly upregulated gene ontology categories from the Uniprot GO ID database (Table 3 and S7 Table) and REVIGO [71] was used to visualize biological processes that were significantly overrepresented in the WNS-affected transcriptome (Fig 4). The functional analysis revealed that $P d$ infection increases expression of genes involved in metabolism, defense responses, and other pathways (Table 3). 
Table 3. Selected over-represented gene ontology biological process categories.

\begin{tabular}{|c|c|c|c|c|c|c|}
\hline Category & GO: Biological Process Term & $p^{1}$ & FDR $^{2}$ & Enrich $^{3}$ & \# $\mathrm{DE}^{4}$ & \# Cat ${ }^{5}$ \\
\hline 0051246 & regulation of protein metabolic process & 4.2E-15 & $5.3 E-11$ & 1.46 & 344 & 1810 \\
\hline 0006952 & defense response & 2.3E-10 & $2.2 \mathrm{E}-07$ & 1.56 & 179 & 881 \\
\hline 0051248 & negative regulation of protein metabolic process & 4.3E-10 & $2.9 \mathrm{E}-07$ & 1.61 & 156 & 746 \\
\hline 0080134 & regulation of response to stress & $9.9 \mathrm{E}-09$ & 4.6E-06 & 1.46 & 194 & 1019 \\
\hline 0044403 & symbiosis, encompassing mutualism through parasitism & $3.4 \mathrm{E}-08$ & $1.2 \mathrm{E}-05$ & 1.64 & 113 & 528 \\
\hline 0006953 & acute-phase response & $3.5 \mathrm{E}-07$ & $8.9 \mathrm{E}-05$ & 4.11 & 15 & 28 \\
\hline 0034097 & response to cytokine & $1.0 \mathrm{E}-06$ & $2.1 \mathrm{E}-04$ & 1.88 & 58 & 237 \\
\hline 0045089 & positive regulation of innate immune response & 1.1E-06 & 2.1E-04 & 1.89 & 57 & 232 \\
\hline 0006954 & inflammatory response & $1.1 \mathrm{E}-06$ & 2.1E-04 & 1.81 & 64 & 271 \\
\hline 0030216 & keratinocyte differentiation & $3.8 \mathrm{E}-06$ & $5.4 \mathrm{E}-04$ & 3.14 & 18 & 44 \\
\hline 0070555 & response to interleukin-1 & 7.5E-06 & $9.5 \mathrm{E}-04$ & 2.92 & 19 & 50 \\
\hline 0002526 & acute inflammatory response & 8.4E-06 & $1.0 \mathrm{E}-03$ & 3.11 & 17 & 42 \\
\hline 0002755 & MyD88-dependent toll-like receptor signaling pathway & 1.7E-05 & $1.8 \mathrm{E}-03$ & 2.56 & 22 & 66 \\
\hline 0034162 & toll-like receptor 9 signaling pathway & 4.1E-05 & $3.5 \mathrm{E}-03$ & 2.56 & 20 & 60 \\
\hline 0050860 & negative regulation of $\mathrm{T}$ cell receptor signaling pathway & 5.7E-05 & $4.5 \mathrm{E}-03$ & 4.72 & 8 & 13 \\
\hline 2000378 & negative regulation of reactive oxygen species metabolic process & 8.7E-05 & $6.3 \mathrm{E}-03$ & 3.52 & 11 & 24 \\
\hline 0009913 & epidermal cell differentiation & 9.0E-05 & $6.5 \mathrm{E}-03$ & 2.44 & 20 & 63 \\
\hline 0030593 & neutrophil chemotaxis & 1.3E-04 & 9.1E-03 & 3.02 & 13 & 33 \\
\hline 0002223 & stimulatory C-type lectin receptor signaling pathway & 2.3E-04 & 1.4E-02 & 2.01 & 27 & 103 \\
\hline 0050878 & regulation of body fluid levels & 2.7E-04 & 1.6E-02 & 1.43 & 88 & 472 \\
\hline 0051005 & negative regulation of lipoprotein lipase activity & $2.9 \mathrm{E}-04$ & 1.7E-02 & 7.68 & 4 & 4 \\
\hline 0032480 & negative regulation of type I interferon production & 3.7E-04 & 2.1E-02 & 2.77 & 13 & 36 \\
\hline
\end{tabular}

${ }^{1}$ Over-represented $p$ value.

${ }^{2}$ False discovery rate after Benjamini-Hochberg adjustment for multiple comparisons.

${ }^{3}$ Enrichment of differentially expressed genes in this category.

${ }^{4}$ Number of differentially expressed genes in this category identified by GOrilla at a p value cutoff of 0.001 .

${ }^{5}$ Number of genes in this GO category represented in the background set.

For the transcripts that showed lower expression in WNS-affected tissue (Fig 2), the same analysis was performed. Of the 1152 identified transcripts that were downregulated at an FDR of 0.1, 694 homologous human genes were identified by BLAST and mapped to Ensembl gene IDs (S6 Table). GOrilla did not identify any Biological Process categories that were significantly downregulated in the WNS-affected bat tissue.

\section{Host-Pathogen Interactions during WNS}

To examine the gene expression of the $P d$ pathogen using a dual RNA-Seq approach [72], we separately generated a genome-guided Trinity assembly ( 33 Dataset) with the Broad Institute G. destructans genome. The reads from each of the WNS-affected tissues were mapped onto this assembly with Bowtie and gene expression estimated using RSEM (S4 Dataset). Expression levels for the $P d$ genes with the greatest variance are shown in Fig 5. Hierarchical clustering (Fig 6) and principal component analysis (S2 Fig) of the differentially expressed transcripts indicated that $P d$ gene expression was most similar in the wing tissues from bats obtained from the same hibernaculum (Table 1). The expression patterns of $P d$ genes were more similar for KY06, KY07, and KY11, which corresponds to bats captured in Cave 1 in Kentucky, and for KY19 and KY23, which were captured from Cave 2. 


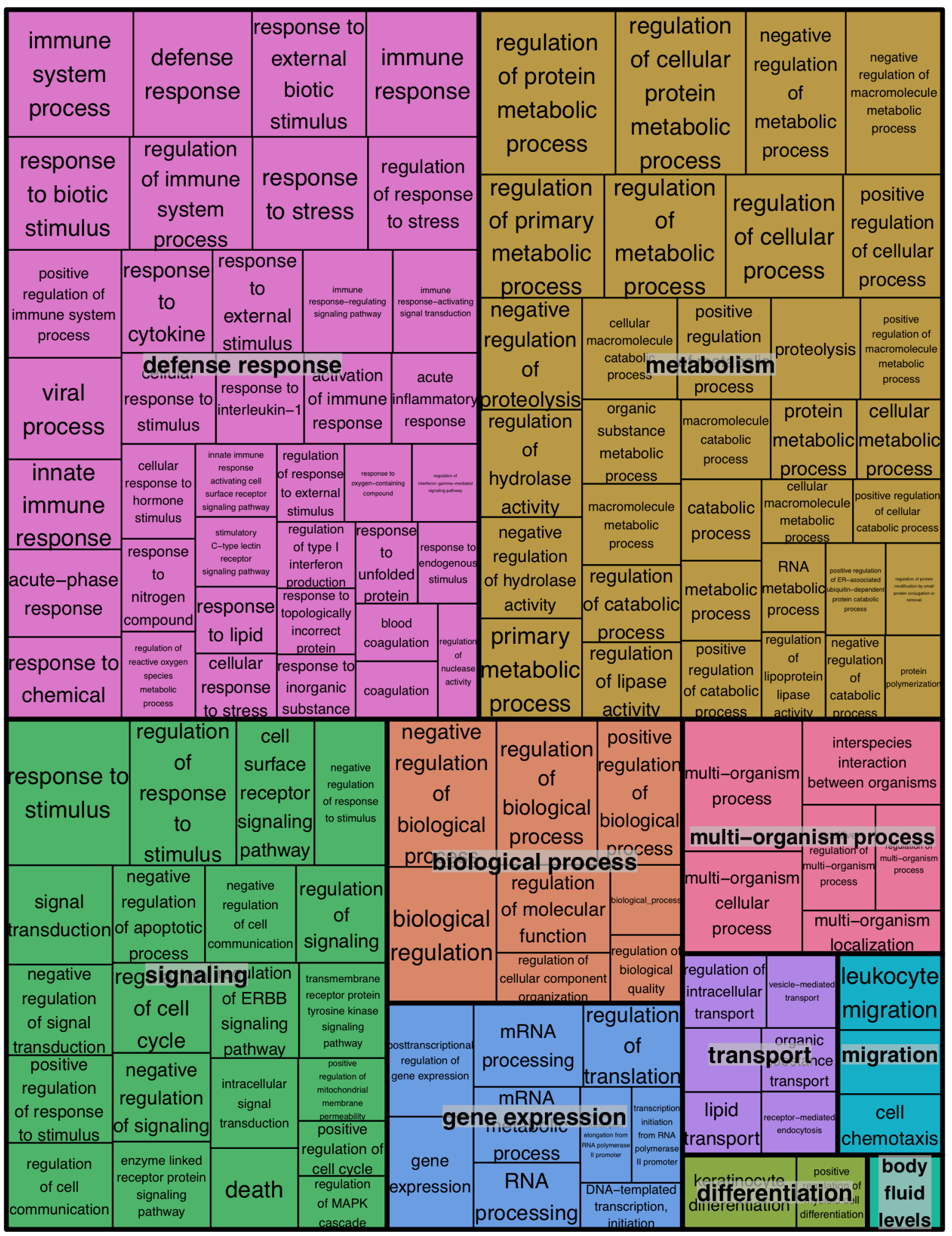

Fig 4. REVIGO treemap summarizing gene ontology biological process categories over-represented in WNS-affected tissues. GOrilla was used to identify Gene Ontology Biological Processes that were over-represented among transcripts more highly expressed in WNS-affected tissues at an FDR cutoff of 0.1 (S6 Table). Over-represented categories with $p$ values of less than 0.001 ( 290 terms) were used to generate a treemap colored by functional category. The size of each rectangle is proportional to the $p$ value for that category.

doi:10.1371/journal.ppat.1005168.g004 


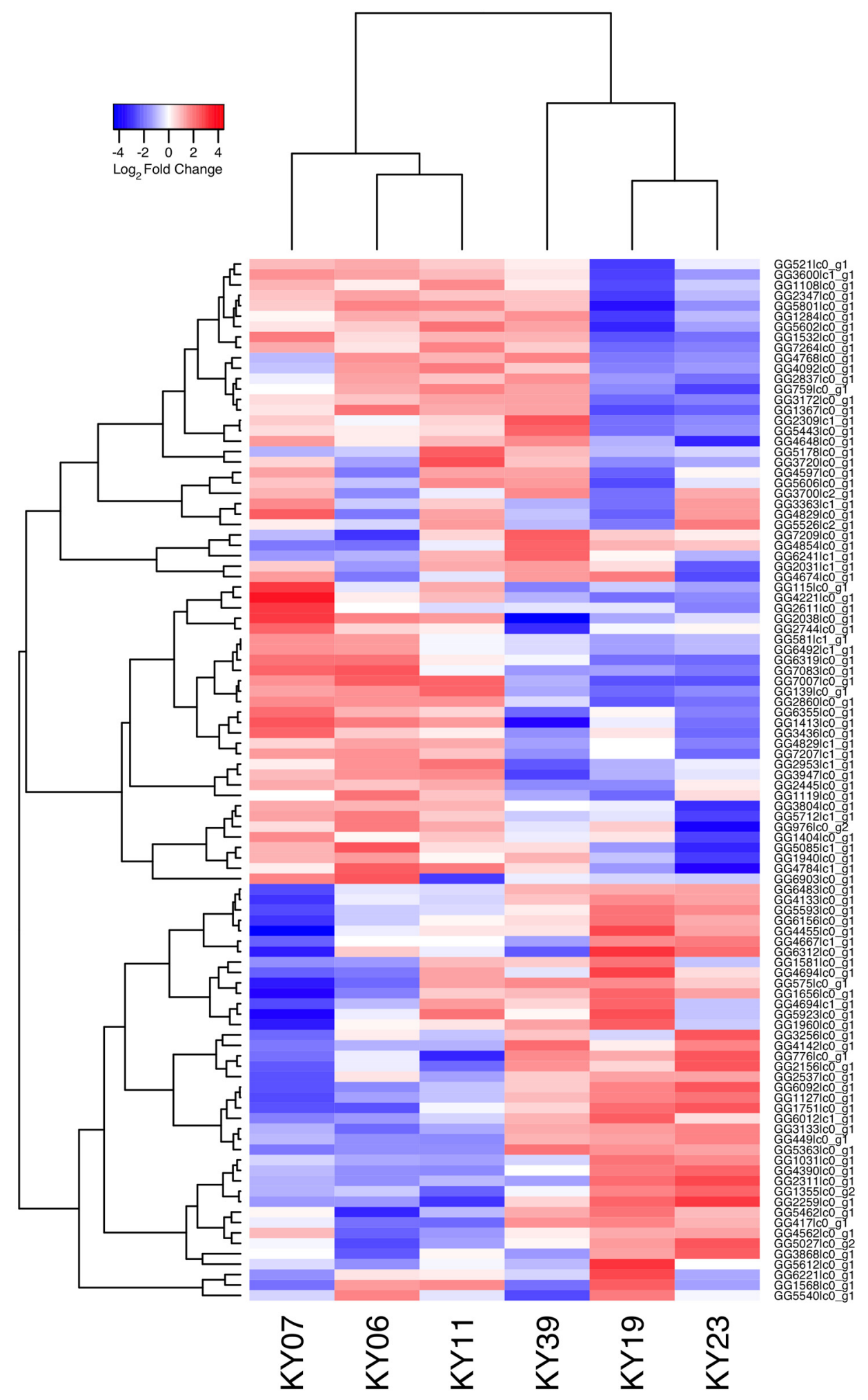

Fig 5. Transcriptional analysis of $P \boldsymbol{d}$ gene expression on bats with WNS. Centered $\log _{2}$ fold changes are shown for 100 Pd genes with the greatest variance and a minimum TMM-normalized FPKM expression of 1 in all 6 samples. The heatmap is scaled from a minimum of -4.4 to a maximum of 4.4 .

doi:10.1371/journal.ppat.1005168.g005 


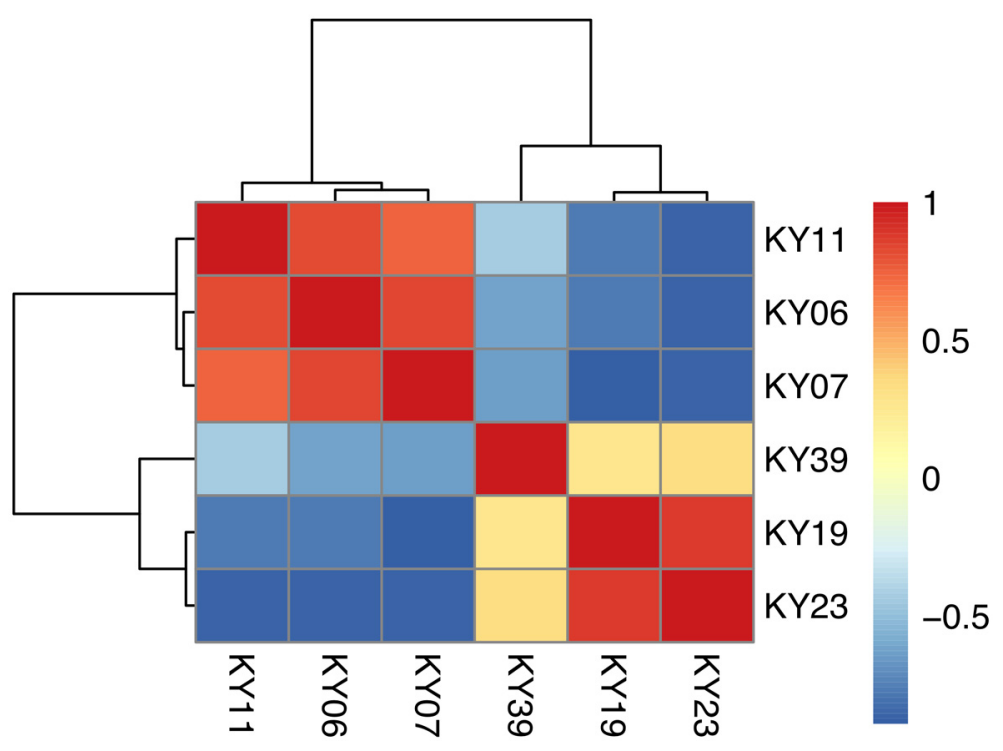

Fig 6. Hierarchical clustering of $\boldsymbol{P d}$ gene expression on bats with WNS. Hierarchical clustering of differentially expressed Pd genes using Pearson correlation complete-linkage clustering. Scale shows Pearson correlation coefficient.

doi:10.1371/journal.ppat.1005168.g006

The possible functions of the $P d$ genes expressed among the WNS-affected samples were analyzed by sequence homology. We first examined the expression levels of a family of secreted proteases that have been proposed to be involved in Pd virulence $[73,74]$ and found that these alkaline proteases were expressed by $P d$ in all 6 wing samples (Table 4). Destructin-2 was the most highly expressed isoform in all WNS-affected bat $P d$ samples.

We next examined the $P d$ transcript clusters for additional factors that could affect virulence. Alignment by BLAST to the Swissprot and Uniprot90 databases identified 12056 transcripts with significant homology to known fungal genes (S8 Table). For the remaining $67 \mathrm{Pd}$ transcript clusters, Trinotate was not able to identify known functional domains or signal peptides present in these previously uncharacterized $P d$ transcripts. The results from the BLAST alignment were examined for genes known to be involved in processes that could affect $P d$ virulence, such as secreted proteases [73-75], metal binding proteins [76], fungal cell wall remodeling [76, 77], and other virulence factors $[75,77,78]$. This analysis identified $46 P d$ genes that could be involved in pathogenesis (Table 5), including additional secreted proteases that could be involved in tissue invasion.

Table 4. Expression of destructin transcripts in Pd growing on WNS-affected bats.

\begin{tabular}{|c|c|c|c|c|c|c|c|c|c|}
\hline Isoform & $\begin{array}{l}\text { UniProt } \\
\text { Match }\end{array}$ & Protein Name & Putative Function(s) & KY06 $^{1}$ & KY07 & KY11 & KY19 & KY23 & KY39 \\
\hline $\begin{array}{l}\text { GG4320| } \\
\text { c0_g1_i1 }\end{array}$ & ALP_ACRCH & $\begin{array}{l}\text { Destructin-2 (Alkaline } \\
\text { protease-2) }\end{array}$ & $\begin{array}{l}\text { Subtilisin-family alkaline } \\
\text { protease }\end{array}$ & 1004 & 711.7 & 1038 & 3696 & 4437 & 1157 \\
\hline $\begin{array}{l}\text { GG6167| } \\
\text { c0_g1_i1 }\end{array}$ & ORYZ_ASPCL & $\begin{array}{l}\text { Destructin-1 (Alkaline } \\
\text { protease-1) }\end{array}$ & $\begin{array}{l}\text { Subtilisin-family alkaline } \\
\text { protease }\end{array}$ & 516.8 & 107.4 & 720.0 & 779.4 & 192.4 & 128.5 \\
\hline $\begin{array}{l}\text { GG5612 } \\
\text { c0_g1_i1 }\end{array}$ & ORYZ_NEOFI & Destructin-3 & $\begin{array}{l}\text { Subtilisin-family alkaline } \\
\text { protease }\end{array}$ & 8.3 & 19.2 & 23.6 & 231.1 & 26.2 & 12.9 \\
\hline
\end{tabular}

\footnotetext{
${ }^{1}$ Trimmed mean of M-values- (TMM-) normalized expression determined by RSEM in fragments per kilobase of transcript per million mapped reads
} (FPKM). 
Table 5. Possible virulence genes expressed in Pd growing on WNS-affected bats.

\begin{tabular}{|c|c|c|c|c|c|c|c|c|c|}
\hline \multirow[t]{2}{*}{ Pd Gene } & \multirow[t]{2}{*}{ UniProt Match } & \multirow[t]{2}{*}{ Protein Name } & \multirow[t]{2}{*}{ Putative Function } & \multicolumn{6}{|c|}{$\begin{array}{l}\text { TMM-normalized expression by RSEM } \\
\text { (FPKM) }\end{array}$} \\
\hline & & & & KY06 & KY07 & KY11 & KY19 & KY23 & KY39 \\
\hline $\begin{array}{l}\text { GG1839| } \\
\text { c0_g1 }\end{array}$ & MSBP2_ARATH & Membrane steroid-binding protein 2 & Antimicrobial peptide response & 63.6 & 146.4 & 30.1 & 24.8 & 65.3 & 48.2 \\
\hline $\begin{array}{l}\text { GG5000 } \\
\text { c0_g1 }\end{array}$ & DUR3_YEAST & Urea active transporter & $\begin{array}{l}\text { Antimicrobial peptide } \\
\text { susceptibility }\end{array}$ & 65.7 & 79.5 & 107.0 & 51.6 & 19.8 & 14.6 \\
\hline $\begin{array}{l}\text { GG5000 } \\
\text { c1_g1 }\end{array}$ & DUR31_SCHPO & Probable urea active transporter 1 & $\begin{array}{l}\text { Antimicrobial peptide } \\
\text { susceptibility }\end{array}$ & 0 & 79.5 & 0 & 81.1 & 102.1 & 0 \\
\hline $\begin{array}{l}\text { GG680| } \\
\text { c0_g1 }\end{array}$ & GMDG_00178 & Uncharacterized protein & Drug resistance transporter & 0 & 29.7 & 24.4 & 141.0 & 175.2 & 39.8 \\
\hline $\begin{array}{l}\text { GG2580 } \\
\text { c0_g1 }\end{array}$ & SOL5_ALTSO & Bifunctional solanapyrone synthase & $\begin{array}{l}\text { Phytotoxin synthesis, } \\
\text { Pathogenesis }\end{array}$ & 101.4 & 0 & 0 & 157.3 & 99.2 & 0 \\
\hline $\begin{array}{l}\text { GG6092 } \\
\text { c0_g1 }\end{array}$ & SOL5_ALTSO & Bifunctional solanapyrone synthase & $\begin{array}{l}\text { Phytotoxin synthesis, } \\
\text { Pathogenesis }\end{array}$ & 66.4 & 35.8 & 113.6 & 714.7 & 1116 & 352.5 \\
\hline $\begin{array}{l}\text { GG3668 } \\
\text { c0_g1 }\end{array}$ & TOXA_COCCA & $\begin{array}{l}\text { Putative HC-toxin efflux carrier } \\
\text { TOXA }\end{array}$ & Toxin transporter & 20.4 & 0 & 77.5 & 143.8 & 85.0 & 62.7 \\
\hline $\begin{array}{l}\text { GG3668 } \\
\text { c1_g1 }\end{array}$ & TOXA_COCCA & $\begin{array}{l}\text { Putative HC-toxin efflux carrier } \\
\text { TOXA }\end{array}$ & Toxin transporter & 78.6 & 0 & 74.4 & 122.5 & 40.1 & 0 \\
\hline $\begin{array}{l}\text { GG432| } \\
\text { c0_g1 }\end{array}$ & TOXA_COCCA & $\begin{array}{l}\text { Putative HC-toxin efflux carrier } \\
\text { TOXA }\end{array}$ & Toxin transporter & 114.0 & 35.1 & 54.2 & 89.5 & 131.9 & 53.1 \\
\hline $\begin{array}{l}\text { GG432 } \\
\text { c1_g1 }\end{array}$ & TOXA_COCCA & $\begin{array}{l}\text { Putative HC-toxin efflux carrier } \\
\text { TOXA }\end{array}$ & Toxin transporter & 42.5 & 49.0 & 20.2 & 66.5 & 132.5 & 0 \\
\hline $\begin{array}{l}\text { GG680| } \\
\text { c1_g1 }\end{array}$ & TOXA_COCCA & $\begin{array}{l}\text { Putative HC-toxin efflux carrier } \\
\text { TOXA }\end{array}$ & Toxin transporter & 27.1 & 20.9 & 12.9 & 148.7 & 198.9 & 0 \\
\hline $\begin{array}{l}\text { GG1568 } \\
\text { c0_g1 }\end{array}$ & CHI1_COCP7 & Endochitinase 1 & Fungal cell wall & 305.2 & 26.9 & 348.1 & 581.9 & 46.0 & 27.2 \\
\hline $\begin{array}{l}\text { GG2156 } \\
\text { c0_g1 }\end{array}$ & YCZ2_SCHPO & $\begin{array}{l}\text { Putative mannan endo-1,6-alpha- } \\
\text { mannosidase }\end{array}$ & Fungal cell wall & 32.5 & 6.3 & 7.7 & 57.4 & 214.3 & 113.9 \\
\hline $\begin{array}{l}\text { GG1843 } \\
\text { c0_g1 }\end{array}$ & ENG1_SCHPO & Endo-1,3(4)-beta-glucanase 1 & Fungal cell wall & 77.7 & 0 & 62.1 & 196.4 & 8.6 & 26.0 \\
\hline $\begin{array}{l}\text { GG2744 } \\
\text { c0_g1 }\end{array}$ & BGLE_NEOFI & Probable beta-glucosidase $\mathrm{E}$ & Fungal cell wall & 115.2 & 355.1 & 84.6 & 65.8 & 77.6 & 8.2 \\
\hline $\begin{array}{l}\text { GG2744| } \\
\text { c1_g1 }\end{array}$ & BGLE_NEOFI & Probable beta-glucosidase $\mathrm{E}$ & Fungal cell wall & 0 & 238.0 & 0 & 0 & 124.6 & 0 \\
\hline $\begin{array}{l}\text { GG4455 } \\
\text { c0_g1 }\end{array}$ & AVR4_PASFU & Race-specific elicitor A4 & Fungal cell wall, Pathogenesis & 106.3 & 5.1 & 158.0 & 866.6 & 309.2 & 166.0 \\
\hline $\begin{array}{l}\text { GG2938 } \\
\text { c0_g1 }\end{array}$ & BGBP_PENMO & Beta-1,3-glucan-binding protein & Innate immune activation & 121.2 & 85.2 & 150.4 & 34.5 & 68.4 & 104.5 \\
\hline $\begin{array}{l}\text { GG2938 } \\
\text { c0_g2 }\end{array}$ & BGBP_PENMO & Beta-1,3-glucan-binding protein & Innate immune activation & 840.1 & 332.2 & 768.8 & 783.6 & 476.6 & 339.3 \\
\hline $\begin{array}{l}\text { GG6498 } \\
\text { c0_g1 }\end{array}$ & SR1A_PHYPO & Spherulin-1A & Manganese binding & 1067 & 629.2 & 1202 & 217.1 & 373.4 & 6328 \\
\hline $\begin{array}{l}\text { GG3236 } \\
\text { c0_g1 }\end{array}$ & SBNA_RALME & Pd uncharacterized protein L8FZ85 & Siderophore biosynthesis & 68.3 & 205.4 & 60.5 & 48.3 & 192.0 & 0 \\
\hline $\begin{array}{l}\text { GG4315 } \\
\text { c0_g2 }\end{array}$ & FRE3_YEAST & $\begin{array}{l}\text { Ferric reductase transmembrane } \\
\text { component } 3\end{array}$ & $\begin{array}{l}\text { Siderophore transport, Iron } \\
\text { binding }\end{array}$ & 157.9 & 86.4 & 135.7 & 76.1 & 86.4 & 95.6 \\
\hline $\begin{array}{l}\text { GG5300 } \\
\text { c0_g1 }\end{array}$ & FRE3_YEAST & $\begin{array}{l}\text { Ferric reductase transmembrane } \\
\text { component } 3\end{array}$ & $\begin{array}{l}\text { Siderophore transport, Iron } \\
\text { binding }\end{array}$ & 2422 & 1441 & 1623 & 510.9 & 400.3 & 197.0 \\
\hline $\begin{array}{l}\text { GG6235 } \\
\text { c0_g1 }\end{array}$ & SIT1_YEAST & Siderophore iron transporter 1 & Siderophore transporter & 0 & 0 & 0 & 23.1 & 135.3 & 0 \\
\hline $\begin{array}{l}\text { GG6235 } \\
\text { c0_g2 }\end{array}$ & SIT1_YEAST & Siderophore iron transporter 2 & Siderophore transporter & 115.7 & 133.8 & 170.1 & 191.2 & 74.4 & 107.0 \\
\hline
\end{tabular}


Table 5. (Continued)

\begin{tabular}{|c|c|c|c|c|c|c|c|c|c|}
\hline \multirow[t]{2}{*}{ Pd Gene } & \multirow[t]{2}{*}{ UniProt Match } & \multirow[t]{2}{*}{ Protein Name } & \multirow[t]{2}{*}{ Putative Function } & \multicolumn{6}{|c|}{$\begin{array}{l}\text { TMM-normalized expression by RSEM } \\
\text { (FPKM) }\end{array}$} \\
\hline & & & & KY06 & KY07 & KY11 & KY19 & KY23 & KY39 \\
\hline $\begin{array}{l}\text { GG2118 } \\
\text { c0_g2 }\end{array}$ & ZRT1_YEAST & Zinc-regulated transporter 1 & Zinc transporter & 1873 & 1637 & 1447 & 924.5 & 1211 & 501.3 \\
\hline $\begin{array}{l}\text { GG5016 } \\
\text { c0_g2 }\end{array}$ & ZRT1_YEAST & Zinc-regulated transporter 2 & Zinc transporter & 457.4 & 310.7 & 449.3 & 66.9 & 137.0 & 564.1 \\
\hline $\begin{array}{l}\text { GG3064 } \\
\text { c0_g1 }\end{array}$ & MIRB_EMENI & Siderophore iron transporter mirB & $\begin{array}{l}\text { Response to iron ion } \\
\text { starvation }\end{array}$ & 547.5 & 169.3 & 220.7 & 136.1 & 425.8 & 259.6 \\
\hline $\begin{array}{l}\text { GG861| } \\
\text { c0_g1 }\end{array}$ & MIRB_EMENI & Siderophore iron transporter mirB & $\begin{array}{l}\text { Response to iron ion } \\
\text { starvation }\end{array}$ & 656.0 & 410.1 & 712.3 & 913.4 & 1324 & 541.4 \\
\hline $\begin{array}{l}\text { GG4694 } \\
\text { c1_g1 }\end{array}$ & LAC2_PODAS & Laccase-2 & Melanin biosynthesis & 64.2 & 19.8 & 329.4 & 553.8 & 69.1 & 179.0 \\
\hline $\begin{array}{l}\text { GG6611 } \\
\text { c0_g1 }\end{array}$ & UREA_ASPFU & Urease & Nitrogen metabolism & 49.8 & 0 & 0 & 38.8 & 151.1 & 222.7 \\
\hline $\begin{array}{l}\text { GG6611 } \\
\text { c1_g1 }\end{array}$ & UREA_ASPFU & Urease & Nitrogen metabolism & 0 & 28.2 & 34.8 & 28.6 & 112.6 & 0 \\
\hline $\begin{array}{l}\text { GG6611 } \\
\text { c3_g1 }\end{array}$ & UREA_ASPFU & Urease & Nitrogen metabolism & 0 & 54.8 & 0 & 55.7 & 142.6 & 0 \\
\hline $\begin{array}{l}\text { GG6612 } \\
\text { c0_g1 }\end{array}$ & UREA_ASPFU & Urease & Nitrogen metabolism & 0 & 0 & 0 & 499.6 & 0 & 0 \\
\hline $\begin{array}{l}\text { GG3518 } \\
\text { c0_g1 }\end{array}$ & ALL2_ASPFU & Major allergen Asp f 2 & $\begin{array}{l}\text { Metallopeptidase, Fungal } \\
\text { allergen }\end{array}$ & 2789 & 4105 & 1021 & 3510 & 5373 & 449.6 \\
\hline $\begin{array}{l}\text { GG2311 } \\
\text { c0_g1 }\end{array}$ & PRTA_ASPNG & Aspergillopepsin-2 & Aspartic endopeptidase & 59.3 & 79.9 & 84.5 & 709.2 & 1149 & 68.8 \\
\hline $\begin{array}{l}\text { GG2082 } \\
\text { c0_g1 }\end{array}$ & PEPA_ASPOR & Aspartic protease pep1 & $\begin{array}{l}\text { Secreted aspartic } \\
\text { endopeptidase }\end{array}$ & 64.5 & 31.0 & 45.9 & 95.5 & 370.1 & 0 \\
\hline $\begin{array}{l}\text { GG2082 } \\
\text { c0_g2 }\end{array}$ & PEPA_ASPOR & Aspartic protease pep1 & $\begin{array}{l}\text { Secreted aspartic } \\
\text { endopeptidase }\end{array}$ & 0.1 & 0.1 & 0.1 & 189.7 & 5.1 & 0 \\
\hline $\begin{array}{l}\text { GG4492 } \\
\text { c0_g1 }\end{array}$ & CARP_CRYPA & Endothiapepsin & $\begin{array}{l}\text { Secreted aspartic } \\
\text { endopeptidase }\end{array}$ & 648.7 & 460.5 & 311.8 & 406.5 & 423.6 & 216.0 \\
\hline $\begin{array}{l}\text { GG448| } \\
\text { c0_g1 }\end{array}$ & LAP1_SCLS1 & Leucine aminopeptidase 1 & Secreted leucyl endopeptidase & 100.7 & 84.0 & 95.7 & 283.3 & 265.6 & 183.0 \\
\hline $\begin{array}{l}\text { GG788| } \\
\text { c0_g1 }\end{array}$ & SPM1_MAGO7 & Subtilisin-like proteinase Spm1 & $\begin{array}{l}\text { Secreted serine } \\
\text { endopeptidase }\end{array}$ & 956.8 & 952.7 & 525.5 & 1260 & 1176 & 919.4 \\
\hline $\begin{array}{l}\text { GG2765 } \\
\text { c0_g1 }\end{array}$ & PEPS_ASPPH & Carboxypeptidase cpdS & Serine carboxypeptidase & 83.2 & 114.5 & 146.9 & 775.2 & 981.3 & 408.6 \\
\hline $\begin{array}{l}\text { GG3562 } \\
\text { c1_g1 }\end{array}$ & SED4_ARTOC & Tripeptidyl-peptidase SED4 & $\begin{array}{l}\text { Serine endopeptidase, } \\
\text { Pathogenesis }\end{array}$ & 715.7 & 366.5 & 690.3 & 1703 & 2009 & 191.9 \\
\hline $\begin{array}{l}\text { GG2259 } \\
\text { c0_g1 }\end{array}$ & SOD6_CANAL & $\begin{array}{l}\text { Cell surface superoxide dismutase } \\
\text { [Cu-Zn] } 6\end{array}$ & $\begin{array}{l}\text { Superoxide metabolism, } \\
\text { Pathogenesis }\end{array}$ & 43.5 & 44.6 & 13.8 & 556.7 & 880.6 & 179.3 \\
\hline $\begin{array}{l}\text { GG4408 } \\
\text { c0_g1 }\end{array}$ & CCPR2_ASPFU & Putative heme-binding peroxidase & $\begin{array}{l}\text { Oxidative stress response, Iron } \\
\text { binding }\end{array}$ & 1044 & 842.8 & 477.1 & 63.0 & 42.3 & 421.4 \\
\hline $\begin{array}{l}\text { GG6788| } \\
\text { c0_g1 }\end{array}$ & HOG1_CRYPA & $\begin{array}{l}\text { Mitogen-activated protein kinase } \\
\text { HOG1 }\end{array}$ & $\begin{array}{l}\text { Virulence and conidia } \\
\text { formation }\end{array}$ & 735.1 & 816.2 & 959.1 & 325.7 & 373.5 & 772.8 \\
\hline
\end{tabular}

doi:10.1371/journal.ppat.1005168.t005

Because the tissue samples were collected from bats from 6 different hibernacula for this study, it is possible that differences in host or pathogen gene expression reflect differences in the environmental conditions present in each location, including the microbiome. In addition, the housing of the unaffected bats in captivity for 13 weeks prior to analysis could also have affected the microbiome. To examine the differences in the skin microbiome between the bats, we used MG-RAST to identify the lowest common ancestor of metagenomic sequences present 
(S8 Table). Although there were some differences observed in the bacterial microbiomes present on the wings of the 11 bats, there were no significant changes between the WNS-affected and unaffected samples when bacteria were identified at the class level. Several strains of Pseudomonas fluorescens isolated from bat tissues have been identified with $P d$ growth inhibiting properties [79]. MG-RAST analysis showed that Pseudomonas species are present in all 11 samples (S8 Table). P. fluorescens transcripts represented $2.8 \pm 0.6 \%$ of transcripts identified from gammaproteobacteria and $0.40 \pm 0.05 \%$ of all bacteria on the wings of unaffected bats and $0.37 \pm 0.07 \%$ of all bacteria on WNS-affected bats. P. fluorescens was present on all little brown myotis sampled, but was rare and relative abundance was not statistically different between WNS-affected and unaffected bats $(\mathrm{p}=0.49, \mathrm{t}=-0.71, \mathrm{df}=9)$.

\section{Discussion}

The comparison of host gene expression between WNS-affected and unaffected little brown myotis clearly demonstrates that $P d$ infection causes physiological responses in wing tissue, where substantial fungal invasion of the skin occurs in WNS-affected bats [8]. The changes in transcript levels that we have observed indicate that host responses to fungal infection remain intact during hibernation and are similar to those observed during the initial stages of fungal infection in euthermic mammals [32]. These host responses include acute inflammation, wound healing, and metabolic changes. Pathogen gene expression varies among bats with WNS, suggesting host-pathogen interactions that mediate pathogenesis. Together, these results lay a foundation to determine which host and pathogen responses contribute to WNS resistance and susceptibility and identify targets to increase survival.

\section{Host Response to $P d$ Infection}

The gene expression changes we observed in the wing tissue of WNS-affected bats are similar to those observed in other cutaneous fungal infections [80]. Cutaneous Candida albicans infections in humans and mice typically initiate an immune response by activating pattern recognition receptors of the C-type lectin family [81-83] and the toll-like receptor family, both of which we found upregulated in WNS-affected bat wing tissue (S4 Table). These included Ctype lectin domain (CLEC) family members CLEC4D (MCL), CLEC4E (MINCLE), CLEC7A (Dectin-1), CLEC6A (Dectin-2), and Toll-like receptor 9. In mice and humans, protective host responses to C. albicans are usually characterized by many of the same cytokines and chemokines [29] that we have found upgregulated in WNS-affected wing tissue, including the cytokines IL-1 $\beta$, IL-6, G-CSF, IL-23A, and IL-17C. Little brown myotis infected with $P d$ are increasing transcription of the key genes necessary for initiating a host response that provides protection from fungal infection. This clearly demonstrates that hibernation does not prevent innate immune responses in bats infected with $P d$ and that, although they are not closely related to rodents and primates [41], bats respond to fungal infections similarly to these other mammals.

The responses to $P d$ infection within bat wing tissue may be mediated by keratinocytes in the epithelial tissue. Activation of pattern recognition receptors by fungal ligands is expected to induce keratinocytes to produce many of the cytokines that we have found upregulated at the transcript level in WNS-affected bat wing tissue [84]. In addition to the cytokines typically involved in C. albicans responses described above, keratinocytes are also known to express the chemokine Ccl2 and the cytokines IL-20 and IL-24 in response to pattern recognition receptor activation [85]. Keratinocytes and fibroblasts are also known to exhibit a paracrine loop of IL-1 and IL-6 activation [86] that enhances wound healing and host defense to microbial infection and we found evidence of IL-1 and IL-6 receptor activation in the increased RNA levels for 
transcription factor p65, NFkB, and P-selectin glycoprotein ligand 1 (S4 Table). Another important cytokine produced by epithelial cells in response to infection is IL-17C [87]. This is an atypical IL-17 family member that is expressed by epithelial cells and causes autocrine responses in the epithelial cells that also express the IL-17RA and IL-17RE heterodimeric IL-17 receptor [87]. The wing tissue transcriptomes from WNS-affected and unaffected bats show similar expression levels of both IL-17RA and IL-17RE (S2 Dataset) and would, therefore, be expected to be responsive to IL-17C. The gene ontology analysis also found evidence for functional enrichment of genes involved in keratinocyte differentiation, presumably due to wound healing responses. Keratinocytes or other epithelial cells in bat wing tissue appear to have responded to the invasion of the epidermis by fungal hyphae.

Genes for pro-inflammatory mediators characterized the innate immune response that we observed in the wing tissue of $P d$ infected bats. Under euthermic conditions this would be expected to provide protection by the recruitment of monocytes and neutrophils, mediated by G-CSF, IL-23A, Ccl2, IL-17C and IL-6 [88], and the initiation of an adaptive Th17 or Th1 response. However, under the constraints of hibernation, responses that require leukocyte migration do not appear to occur in $P d$-infected bats. We do not find strong evidence of increased expression for genes characteristic of either innate or adaptive leukocytes, except for L-selectin, which is expressed on T cells, and CD177, which is expressed on neutrophils. Lower than expected levels of monocyte, neutrophil, Th1, and Th17 cell recruitment may be related to the sequestration of leukocytes during hibernation [45]. However, we have observed neutrophil recruitment in hibernating little brown myotis in response to another fungal infection (Table 1). In the histological examination of the current samples, we found neutrophilic inflammation in both WNS-affected and unaffected wing tissue (Table 1). However, this inflammation did not occur at the sites of $P d$ infection. Curiously, we found a significant increase in WNS-affected tissue for transcripts for $\mathrm{CD} 3 \gamma$ and $\mathrm{CD} 45$ that could be expressed by gammadelta T cells or other innate lymphocytes that reside in the skin [89]. It is possible that $P d$ is specifically suppressing neutrophil and/or T cell recruitment by interfering with chemotactic signals, similar to the suppression of inflammatory immune responses during chytridiomycosis in amphibians [42]. However, analysis of tissue levels of the cytokines and chemokines is necessary to confirm the secretion of these proteins. Because neutrophils and T cells do not appear to be recruited to sites of $P d$ infection during hibernation, only local inflammatory mediators may be available and they appear to be unable to control the infection in little brown myotis.

In addition to immune responses, hibernating bats also respond to $P d$ infection in other ways. We found transcripts for proteins from many pathways involved in metabolism, signaling, gene expression, transport, migration, and differentiation that were altered in WNSaffected bats (Fig 4). We cannot exclude the possibility that some of these differences were due to the different hibernation conditions of the two groups of bats. However, the differential expression of the genes in these pathways demonstrates that they are subject to regulation during hibernation and can respond to infection, tissue damage, and/or environmental changes.

Host responses to fungal infection can be influenced by changes in the pathogen, including gene expression changes in the colonizing fungus, such as C. albicans [29]. We found significant variability in the gene expression by $P d$, which is particularly interesting because all $P d$ in North America is presumed to be a clone of the same mating type [90]. The pathogen has adopted different gene expression profiles in the 6 bat tissues (Fig 5), perhaps in response to differences in the host environments. Correspondingly, host gene expression patterns also show differences between the WNS-affected tissue samples. Of particular interest is the observation that the cytokine and chemokine genes found in principal component 2 of our PCA analysis (Fig 3B and S5 Table) are expressed at very different levels in the $6 P d$-infected samples. From this study we cannot determine whether the differences in pathogen gene expression 
are driven by differences in the host environment or vice versa. Although all 6 WNS-affected bats had visible signs of WNS, had similar $P d$ burdens, and similar histopathology, it is possible that the differences in host or pathogen gene expression that we observed may have affected progression of WNS and survival.

\section{Responses that May Contribute to WNS Mortality}

Because the increased frequency of arousals from torpor appears to be a primary cause of WNS mortality $[5,14,22]$, we considered possible mechanisms that could affect torpor bout length. The increased gene expression of IL-1, IL-6, and other pro-inflammatory cytokines mediates a local acute inflammatory response to $P d$. These cytokines also have systemic effects that modify behavior and thermoregulation [91]. In addition to cytokine and chemokine transcript increases, we also found increased transcripts for the enzyme cyclooxygenase-2 (prostaglandin G/H synthase 2) and both secreted and cytosolic phospholipase A2 that form critical inflammatory lipid mediators such as prostaglandin $\mathrm{H}_{2}$. The eicosanoids generated by these enzymes, along with the actions of the upregulated genes kallikrein- 6 and cathepsin $S$, are expected to generate pain and itching by locally activating neuronal nociceptors [92, 93]. This, in turn, could affect torpor bout length and/or behavior during periodic arousals. Indeed, we have documented significantly more grooming in WNS-affected bats infected in the wild [94], although a different study on laboratory-infected bats did not find similar behavior changes [95]. Together, the upregulated genes will likely generate an inflammatory microenvironment within the wing that may contribute to the robust wound healing response that we observe in WNSaffected bats. However, inflammation can also play a detrimental role in some diseases [96]. Further tissue damage and subsequent wound healing occurs in surviving bats upon emergence from hibernation [19]. These local affects of inflammation (pain and itching) as well as systemic effects are likely to play a key role in WNS pathology.

In addition to the gene expression changes that may contribute to acute inflammation locally within the epithelial tissues invaded by $P d$, the systemic release of febrile cytokines such as IL-6 could affect the signals that control hibernation arousal. However, an exogenous pyrogen, lipopolysaccharide, is not able to provoke arousals in hibernating golden-mantled ground squirrels [97], so it may be unlikely that inflammation or febrile cytokines can directly trigger arousal in WNS-affected bats. Intracerebroventricular injection of prostaglandin $E_{2}$ in goldenmantled ground squirrels induces arousal from torpor and a febrile response during an extended periodic arousal [97]. Our observation of increased expression of the enzyme that generates prostaglandin $\mathrm{H}_{2}$ may provide a mechanism that explains the shortened torpor bouts in WNS-affected bats, if it can be shown that this enzyme is active in the tissue and produces enough prostaglandin $\mathrm{H}_{2}$ to act systemically.

In addition to the changes in expression of genes involved in immune responses and wound healing, we also found significant changes in metabolic genes. We found evidence of gene expression changes consistent with increased fat metabolism, including changes in transcripts for apolipoproteins, lipid transport proteins, protein metabolism, and carbohydrate metabolism. Of particular interest, we found increases in the expression of hydroxycarboxylic acid receptors 2 and 3 that are known to mediate adiponectin secretion [98]. This suggests that infection with $P d$ may directly trigger changes in lipid and carbohydrate metabolism that contribute to WNS pathology. These changes stand in contrast to the changes that have been seen in the brain transcriptome of hibernating horseshoe bats (Rhinolophus ferrumequinum) [99] and the brain proteome of hibernating Rickett's big-footed bats (Myotis pilosus) [100], which show decreased fat metabolism during torpor. By leading to premature depletion of fat stores, these gene expression changes could contribute to WNS mortality. 
The other changes in host gene expression that we observed are consistent with a multistage progression model of WNS [22]. We also found support for changes in genes involved in oxidative stress [23] and body fluid levels, which may contribute to WNS progression. Together, the pattern of gene expression changes that we find in little brown myotis with WNS suggests that a combination of maladaptive responses may contribute to mortality. However, the number of upregulated genes involved in the acute inflammatory response suggests that excessive inflammation may also be a factor contributing to pathology even prior to emergence from hibernation when it is suspected to contribute to wing damage [101].

\section{Implications for Future Studies}

The changes in host transcript levels that we have found are presumably caused by physiological responses of the host to infection. However, caution must be used when extending these transcriptional responses to functional mechanisms because the current study does not measure protein or metabolite levels directly. Future studies will be necessary to determine which of the gene expression changes observed affect which host response mechanisms.

The little brown myotis chosen for the WNS-affected samples were exhibiting WNS pathology and appeared unlikely to survive at the time of sample collection. For this reason, it is presently uncertain which of the gene expression changes that we have observed are contributing to protection and which are pathological. Another factor that likely contributes to the variation in gene expression that we observed among the samples collected from free-ranging bats is the time since the most recent arousal from torpor. Prior to collection of each wing tissue sample, bats were artificially aroused for 30 to 120 minutes. This period of arousal is similar in duration to the natural arousals during hibernation for little brown myotis [14], and presumably of sufficient duration for some innate immune responses to occur and for transcript levels to be altered. One reason for this procedure was to avoid disparities between the elapsed time from the most recent arousal bout until tissue collection. For the WNS-affected bats we could not determine when the most recent natural arousal would have occurred, but it would have likely been more recently than in unaffected animals, as affected animals arouse from torpor more frequently [14]. In the current study we cannot resolve whether the changes in gene expression that we observed occurred during the most recent arousal, during previous periodic arousals, or during torpor. Future studies will be needed to determine which of the changes in gene expression that we observed during WNS in bats in the wild also vary in controlled captive hibernation conditions when prior arousal patterns are known. Further studies are also needed to compare the physiological responses in bats exhibiting WNS morbidity to responses in less susceptible bats, such as European species, North American species that are less susceptible like the big brown bat [11], and the remnant populations of little brown myotis that appear to have developed tolerance or resistance to $P d$ [1]. Such studies should point to a path forward for bats in North America to persist in a landscape where $P d$ is endemic.

\section{Conclusions}

Little brown myotis mount a host response to $P d$ infection during hibernation. Which components of this response are protective or contribute to WNS pathology remains to be resolved. The innate immune response we have observed would be expected to promote a Th17-directed adaptive immune response that could clear the infection. However, the energetic constraints of hibernation may prevent little brown myotis from execution of the Th17- and neutrophilmediated phases of the immune response. This may lead to excessive inflammatory responses, either during hibernation or upon emergence. The changes in host gene expression that we observed demonstrate that during $P d$ infection, little brown myotis also alter other defense 
responses, metabolic pathways, and transcription. Numerous $P d$ genes that may contribute to virulence were identified and these represent potential pathogen responses to host defense. Hibernation does not prevent a host response to infection and a better understanding of the differences between host and pathogen responses in bats susceptible to WNS and those resistant may lead to ways for increasing survival.

\section{Materials and Methods Ethics Statement}

This study was carried out on bats from non-endangered species in strict accordance with the recommendations in the Guide for the Care and Use of Laboratory Animals of the National Institutes of Health. All methods were approved by the Institutional Animal Care and Use Committee at Bucknell University (protocol DMR-016). Animals were humanely euthanized by isoflurane anesthesia overdose followed by decapitation. In Illinois, animal collection was conducted by state wildlife officials and a numbered permit was not required. Scientific collector's permits were obtained in Michigan (SC1448), Minnesota (201174), and Kentucky (SC1411147).

\section{Samples}

We collected hibernating little brown myotis from cave or mine walls at the locations listed in Table 1. Bats collected from all locations are expected to be from the same genetic population of eastern little brown myotis [102]. For bats unaffected by WNS, little brown myotis were first swabbed on the left forearm for quantitative PCR analysis. After measurements were taken, bats were individually placed in cloth bags and hung in constant temperature thermoelectric coolers (Koolatron PC-3) maintained at $\sim 7^{\circ} \mathrm{C}$. Water-saturated sponges were placed in the bottom of each cooler to maintain humidity during transportation to Bucknell University. Bats were housed for 13 weeks in a Percival (model I36VLC8) environmental chamber with conditions set to $4^{\circ} \mathrm{C}$ and $95 \%$ relative humidity. Bats were provided water throughout hibernation. Bats were aroused from hibernation for 30-120 minutes prior to euthanasia. For WNS-affected bats, little brown myotis were collected in the field, measured, swabbed for quantitative PCR, and humanely euthanized after being aroused from hibernation for 60-120 minutes. Scaled mass index (SMI) was calculated using the formula (mass(in $\mathrm{g}))^{*}(38.01 /($ forearm length(in $\mathrm{mm}))^{\wedge} 1.406$ [103]. Wing tissue was placed in formalin for histology and placed in RNAlater (Sigma-Aldrich) for gene expression analysis. RNAlater samples were stored at ambient temperature for up to 24 hours before long-term storage at $-80^{\circ} \mathrm{C}$. RNA was purified from $50 \mathrm{mg}$ of wing tissue using a QIAGEN RNeasy Mini Kit. All samples used for RNA sequencing had RNA integrity values greater than 7.0 using an Agilent Bioanalyzer.

\section{Verification of WNS Status}

Wing skin tissue was removed from the bones of the arm and digits and rolled onto $2 \mathrm{~cm}$ paraffin wax logs. The logs were then fixed in $10 \%$ neutral buffered formalin for at least 24 hours. Each $\log$ was cut into 3 pieces that were processed into paraffin blocks overnight in a TissueTek VIP processor (Sakura Finetek). The pieces were embedded in paraffin blocks, sectioned at 3 microns, and stained with periodic acid Schiff with a hematoxylin counterstain [8]. WNS lesions (Table 1; WNS) were identified as cupping erosions with fungal hyphae and conida present. Inflammatory foci (Table 1 ; Infl) were identified as clusters of infiltrating neutrophils and were not associated with the asymmetrical curved conidia of $P d$. 
To determine presence or absence of $P d$ on bats unaffected by WNS, each swab was tested twice by quantitative PCR [64] by Jeffrey T. Foster at University of New Hampshire. A cyclethreshold less than 40 was used as a positive result. One of the 5 unaffected bats had one positive and one negative test (Table 1), but histology (Table 1 ) and subsequent RNA sequencing determined this to most likely be a false positive ( 2 Table; $\mathrm{p}=2.2 \times 10^{-6}$ ). For bats affected by WNS, we performed quantitative PCR to measure the $P d$ load, in genomic equivalents normalized to swabs spiked with $10000 P d$ conidia, that were detected on each bat [15].

\section{Next Generation RNA Sequencing}

The Genome Sequencing and Analysis Facility at the University of Texas at Austin performed all library preparation and quality control procedures. Directional RNA libraries were prepared with poly-A mRNA enrichment, dUTP/UDG strand-specific labeling, fragmentation, and 200 base pair size selection. RNA-Seq was performed in two lanes of an Illumina HiSeq 2500 with 101 base pair length reads obtained.

\section{Transcriptome Assemblies}

The paired reads from all samples were preprocessed by removing adapters and using trimmomatic PE [104] with settings of Illumina clip:2:30:10, seed mismatches:2, palindrome threshold:30, clip threshold:10, leading:5, trailing:5, minlength:36. The remaining paired reads were then combined and Trinity (v2.0.4) was used in strand-specific mode (RF) to construct a de novo assembly [105]. K-mer in silico read normalization with maximum coverage of 50 resulted in 22482456 read pairs that were used for assembly out of 177755004 total. The assembly was then filtered to remove $P d$ sequences using the program Deconseq [65] with the Broad Institute Geomyces destructans genome 20631-21 used to identify pathogen sequences and with the little brown myotis genome (Myoluc2.0) used to retain host sequences. Bowtie 1.0.1 [106] was used to determine the number of reads that mapped to each transcript in the assembly.

\section{Differential Expression}

The script align_and_estimate_abundance.pl included in the Trinity v2.0.6 distribution [105] was used to estimate expression levels for each transcript. Bowtie 1.0.1 [106] was used to map reads (including unpaired reads after quality trimming) from each sample onto the assembly. RSEM v1.2.20 [107] was used to apply an expectation maximization algorithm to predict gene expression counts for each transcript. Expression levels are presented after trimmed mean of $\mathrm{M}$-values (TMM) normalization in fragments per kilobase of transcript per million mapped reads (FPKM). DESeq2 v1.8.1 [67] was used to determine the probability of differential expression for each Trinity transcript cluster that had a minimum RSEM-estimated count, before normalization, of 5 across all samples. For DESeq 2 analysis, the default values for removing outliers and filtering lowly expressed transcripts were used. An alpha value of 0.05 was used instead of the default of 0.1 to decrease the number of differentially expressed genes identified. Posterior probabilities of differential expression for individual transcript isoforms were estimated using a Bayesian approach with EBSeq v1.8.0 [68]. False discovery rate [108] was used to control for multiple comparisons. NCBI BLAST v2.2.29+ [109] was used to identify the highest-ranking match for each isoform in the UniProt Swissprot database (downloaded on Sep 17, 2014) with an e-value cutoff of $1 \times 10^{-5}$.

Hierarchical clustering of samples and genes was performed within R 3.1.2 using the hclust function with the complete linkage method. Bootstrap analysis of clustering was performed 
using the pvclust 1.3-2 package and 1000 replications [69]. Principal component analysis was performed using the prcomp function and visualized with the rgl 0.93 .1098 package.

\section{Gene Ontology}

NCBI BLAST v2.2.29+ [109] was used with an e-value cutoff of $1 \times 10^{-5}$ to identify homologs in the Uniprot Swissprot human protein database (downloaded on Nov 25, 2014) for transcripts significantly upregulated in WNS-affected bat wing tissue with an FDR of less than 0.1 (in order to increase the number of genes prior to subsequent analysis with higher stringency FDR). Unique Ensembl gene IDs were identified for 1144 of the 1922 upregulated transcripts and 481 of the 1356 downregulated transcripts. GOrilla [70] was used with a p value cutoff of 0.001 to identify upregulated or downregulated biological processes by comparison to the background list of 12828 human genes identified by BLAST in the Trinity assembly. Multiple testing correction [108] was used with an FDR cutoff of 0.01 . Results were visualized as a treemap with REVIGO [71].

\section{Pd Gene Analysis}

Trinity v2.0.4 was used to generate a $P d$ assembly in genome-guided mode with jaccard clipping and using the Broad Institute G. destructans genome 20631-21. This assembly was used to assess pathogen gene expression in the samples from WNS-affected bats using RSEM v1.2.20 [107]. Trinotate v2 was used to annotate the $P d$ transcripts by using NCBI BLAST v2.2.29+ [109] and both the Swissprot and Uniref90 databases (downloaded on Sep 17, 2014).

\section{Metagenome Analysis}

Reads for each sample were analyzed using MG-RAST v.3.5 [110] to identify metagenomic sequences after filtering against the $B$. taurus genome (the taxonomically closest genome available for filtering). For assignment of organism abundance, the best hit classification was used with the M5NR database, maximum e-value cutoff of $1 \times 10^{-5}$, minimum identity cutoff of $60 \%$, and minimum alignment length cutoff of 15 .

\section{Supporting Information}

S1 Fig. MA plot of gene expression using the trinity transcriptome assembly. Expression levels for every gene are shown by comparing RSEM-estimated counts to the fold-change in expression between unaffected and WNS-affected bat tissues. Blue points indicate significant differential expression determined by DESeq2 using an FDR cutoff of 0.05 . Genes that are more highly expressed in WNS-affected tissues are found in the lower side of the graph. (TIF)

S2 Fig. Principal component analysis of $\boldsymbol{P} \boldsymbol{d}$ genes. The Trinity utility $\mathrm{PtR}$ was used to conduct principal component analysis on the $P d$ genes with a minimum expression of 10 FPKM. (PDF)

S1 Table. Read statistics of RNA-Seq samples. (DOCX)

S2 Table. FPKM analysis of $P d$-derived transcripts prior to removal. (DOCX)

S3 Table. Transcriptome assembly comparison. (DOCX) 
S4 Table. Differentially expressed genes determined by RSEM and DESeq2 combined with EBSeq and trinotate results.

(XLSX)

S5 Table. Principal component analysis rotation values.

(XLSX)

S6 Table. Differentially expressed genes used for GOrilla analysis.

(XLSX)

S7 Table. Gene ontology biological process categories over-represented in WNS-affected tissues.

(XLSX)

S8 Table. $P d$ gene expression estimated by RSEM combined with trinotate results. (XLSX)

S9 Table. MG-RAST analysis of best hit classification for bacterial genes. (XLSX)

S1 Dataset. FASTA file of de novo assembly of little brown myotis transcriptome. (ZIP)

S2 Dataset. RSEM gene expression matrices used for differential host gene expression calculations.

S3 Dataset. FASTA file of genome-guided trinity assembly of $P d$ transcriptome.

S4 Dataset. RSEM gene expression matrices for $P d$ transcripts.

\section{Acknowledgments}

We thank Marianne Moore, Sarah Bouboulis, Megan Vodzak, Allen Kurta, Brooke Hines, Larisa Bishop-Boros, and Shayne Lumadue for assistance in collecting samples. James W. McMichael III provided technical assistance and performed the Pd qPCR of the WNS-affected samples. Jeffrey Foster performed $P d$ qPCR of the unaffected samples. Cindy Rhone, Gretchen Long, and the rest of the animal care staff at Bucknell University assisted in providing excellent care for the captive animals for this study. We thank Jeremy Dreese and Michael Harvey for technical support with performing bioinformatics analysis on the Bucknell Linux cluster. We acknowledge Brian Haas, Tiago Hori, and the rest of the trinityrnaseq-users mailing list for helpful assistance with data analysis. We thank Scott Hunicke-Smith and the Genome Sequencing and Analysis Facility at the University of Texas at Austin for performing library preparation and RNA sequencing.

\section{Author Contributions}

Conceived and designed the experiments: KAF JSJ DMR. Performed the experiments: KAF SMR EJR MJB. Analyzed the data: KAF. Wrote the paper: KAF JSJ TML DMR.

\section{References}

1. Coleman JT, Reichard JD. (2014) Bat White-Nose Syndrome in 2014: A Brief Assessment Seven Years After Discovery of a Virulent Fungal Pathogen in North America. Outlooks on Pest Management 25: 374-377. 
2. Blehert DS. (2012) Fungal disease and the developing story of bat white-nose syndrome. PLoS Pathog 8: e1002779. doi: 10.1371/journal.ppat.1002779 PMID: 22829763

3. Blehert DS, Hicks AC, Behr M, Meteyer CU, Berlowski-Zier BM, et al. (2009) Bat white-nose syndrome: an emerging fungal pathogen? Science 323: 227-227. doi: 10.1126/science.1163874 PMID: 18974316

4. Lorch JM, Meteyer CU, Behr MJ, Boyles JG, Cryan PM, et al. (2011) Experimental infection of bats with Geomyces destructans causes white-nose syndrome. Nature 480: 376-378. doi: 10.1038/ nature10590 PMID: 22031324

5. Warnecke L, Turner JM, Bollinger TK, Lorch JM, Misra V, et al. (2012) Inoculation of bats with European Geomyces destructans supports the novel pathogen hypothesis for the origin of white-nose syndrome. Proc Natl Acad Sci U S A 109: 6999-7003. doi: 10.1073/pnas.1200374109 PMID: 22493237

6. Verant ML, Boyles JG, Waldrep Jr W, Wibbelt G, Blehert DS. (2012) Temperature-dependent growth of Geomyces destructans, the fungus that causes bat white-nose syndrome.

7. Cryan PM, Meteyer CU, Boyles JG, Blehert DS. (2010) Wing pathology of white-nose syndrome in bats suggests life-threatening disruption of physiology. BMC Biol 8: 135-7007-8-135.

8. Meteyer CU, Buckles EL, Blehert DS, Hicks AC, Green DE, et al. (2009) Histopathologic criteria to confirm white-nose syndrome in bats. Journal of Veterinary Diagnostic Investigation 21: 411-414. PMID: 19564488

9. Turner GG, Reeder DM, Coleman JTH. (2011) A five year assessment of mortality and geographic spread of white-nose syndrome in North American bats and a look to the future. Bat Research News 52: 13-27.

10. Frick WF, Puechmaille SJ, Hoyt JR, Nickel BA, Langwig KE, et al. (2015) Disease alters macroecological patterns of North American bats. Global Ecol Biogeogr 24: 741-749.

11. Frank CL, Michalski A, McDonough AA, Rahimian M, Rudd RJ, et al. (2014) The Resistance of a North American Bat Species (Eptesicus fuscus) to White-Nose Syndrome (WNS). PloS One 9: e113958. doi: 10.1371/journal.pone.0113958 PMID: 25437448

12. Wibbelt G, Puechmaille SJ, Ohlendorf B, Mühldorfer K, Bosch T, et al. (2013) Skin Lesions in European Hibernating Bats Associated with Geomyces destructans, the Etiologic Agent of White-Nose Syndrome. PloS One 8: e74105. doi: 10.1371/journal.pone.0074105 PMID: 24023927

13. Bandouchova H, Bartonicka T, Berkova H, Brichta J, Cerny J, et al. (2015) Pseudogymnoascus destructans: evidence of virulent skin invasion for bats under natural conditions, Europe. Transboundary and Emerging Diseases 62: 1-5. doi: 10.1111/tbed.12282 PMID: 25268034

14. Reeder DM, Frank CL, Turner GG, Meteyer CU, Kurta A, et al. (2012) Frequent arousal from hibernation linked to severity of infection and mortality in bats with white-nose syndrome. PLoS One 7: e38920. doi: 10.1371/journal.pone.0038920 PMID: 22745688

15. Johnson JS, Reeder DM, McMichael JW III, Meierhofer MB, Stern DW, et al. (2014) Host, pathogen, and environmental characteristics predict white-nose syndrome mortality in captive little brown myotis (Myotis lucifugus). PLoS ONE 9: e112502. doi: 10.1371/journal.pone.0112502 PMID: 25409028

16. Geiser F. (2004) Metabolic rate and body temperature reduction during hibernation and daily torpor. Annu Rev Physiol 66: 239-274. PMID: 14977403

17. Thomas DW, Cloutier D. (1992) Evaporative water loss by hibernating little brown bats, Myotis lucifugus. Physiol Zool: 443-456.

18. Thomas DW, Dorais M, Bergeron J. (1990) Winter energy budgets and cost of arousals for hibernating little brown bats, Myotis lucifugus. J Mammal 71: 475-479.

19. Fuller NW, Reichard JD, Nabhan ML, Fellows SR, Pepin LC, et al. (2011) Free-ranging little brown myotis (Myotis lucifugus) heal from wing damage associated with white-nose syndrome. Ecohealth 8: 154-162. doi: 10.1007/s10393-011-0705-y PMID: 21922344

20. Cryan PM, Meteyer CU, Blehert DS, Lorch JM, Reeder DM, et al. (2013) Electrolyte depletion in white-nose syndrome bats. J WildI Dis 49: 398-402. doi: 10.7589/2012-04-121 PMID: 23568916

21. Willis CK, Menzies AK, Boyles JG, Wojciechowski MS. (2011) Evaporative water loss is a plausible explanation for mortality of bats from white-nose syndrome. Integr Comp Biol 51: 364-373. doi: 10. 1093/icb/icr076 PMID: 21742778

22. Verant ML, Meteyer CU, Speakman JR, Cryan PM, Lorch JM, et al. (2014) White-nose syndrome initiates a cascade of physiologic disturbances in the hibernating bat host. BMC Physiol 14: 10. doi: 10. 1186/s12899-014-0010-4 PMID: 25487871

23. Moore MS, Reichard JD, Murtha TD, Nabhan ML, Pian RE, et al. (2013) Hibernating little brown myotis (Myotis lucifugus) show variable immunological responses to white-nose syndrome. PloS One 8: e58976. doi: 10.1371/journal.pone.0058976 PMID: 23527062 
24. Moore MS, Reichard JD, Murtha TD, Zahedi B, Fallier RM, et al. (2011) Specific alterations in complement protein activity of little brown myotis (Myotis lucifugus) hibernating in white-nose syndrome affected sites. PLoS One 6: e27430. doi: 10.1371/journal.pone.0027430 PMID: 22140440

25. LeibundGut-Landmann S, Wüthrich M, Hohl TM. (2012) Immunity to fungi. Curr Opin Immunol 24: 449-458. doi: 10.1016/j.coi.2012.04.007 PMID: 22613091

26. Brown GD. (2011) Innate antifungal immunity: the key role of phagocytes. Annu Rev Immunol 29: 1. doi: 10.1146/annurev-immunol-030409-101229 PMID: 20936972

27. Holland SM, DeLeo FR, Elloumi HZ, Hsu AP, Uzel G, et al. (2007) STAT3 mutations in the hyper-lgE syndrome. N Engl J Med 357: 1608-1619. PMID: 17881745

28. Liu L, Okada S, Kong X, Kreins AY, Cypowyj S, et al. (2011) Gain-of-function human STAT1 mutations impair IL-17 immunity and underlie chronic mucocutaneous candidiasis. J Exp Med 208: 16351648. doi: 10.1084/jem.20110958 PMID: 21727188

29. Gow NA, van de Veerdonk, Frank L, Brown AJ, Netea MG. (2012) Candida albicans morphogenesis and host defence: discriminating invasion from colonization. Nature Reviews Microbiology 10: 112122.

30. Netea MG, Brown GD, Kullberg BJ, Gow NA. (2008) An integrated model of the recognition of Candida albicans by the innate immune system. Nature Reviews Microbiology 6: 67-78. PMID: 18079743

31. Romani L. (2011) Immunity to fungal infections. Nat Rev Immunol 11: 275-288. doi: 10.1038/nri2939 PMID: 21394104

32. Hernández-Santos N, Gaffen SL. (2012) Th17 cells in immunity to Candida albicans. Cell Host \& Microbe 11: 425-435.

33. Kagami S, Rizzo HL, Kurtz SE, Miller LS, Blauvelt A. (2010) IL-23 and IL-17A, but not IL-12 and IL-22, are required for optimal skin host defense against Candida albicans. J Immunol 185: 5453-5462. doi: 10.4049/jimmunol.1001153 PMID: 20921529

34. Smeekens SP, Ng A, Kumar V, Johnson MD, Plantinga TS, et al. (2013) Functional genomics identifies type I interferon pathway as central for host defense against Candida albicans. Nature Communications 4: 1342. doi: 10.1038/ncomms2343 PMID: 23299892

35. Blanco JL, Garcia ME. (2008) Immune response to fungal infections. Vet Immunol Immunopathol 125: 47-70. doi: 10.1016/j.vetimm.2008.04.020 PMID: 18565595

36. De Luca A, Zelante T, D'Angelo C, Zagarella S, Fallarino F, et al. (2010) IL-22 defines a novel immune pathway of antifungal resistance. Mucosal Immunology.

37. Conti HR, Shen F, Nayyar N, Stocum E, Sun JN, et al. (2009) Th17 cells and IL-17 receptor signaling are essential for mucosal host defense against oral candidiasis. J Exp Med 206: 299-311. doi: 10 1084/jem.20081463 PMID: 19204111

38. Brook CE, Dobson AP. (2015) Bats as 'special'reservoirs for emerging zoonotic pathogens. Trends Microbiol 23: 172-180. doi: 10.1016/j.tim.2014.12.004 PMID: 25572882

39. Cogswell-Hawkinson AC, McGlaughlin ME, Calisher CH, Adams R, Schountz T. (2011) Molecular and phylogenetic characterization of cytokine genes from Seba's short-tailed bat (Carollia perspicillata). Open Immunology Journal 4: 31-39.

40. Iha K, Omatsu T, Watanabe S, Ueda N, Taniguchi S, et al. (2009) Molecular cloning and sequencing of the cDNAs encoding the bat interleukin (IL)-2, IL-4, IL-6, IL-10, IL-12p40, and tumor necrosis factoralpha. Journal of Veterinary Medical Science 71: 1691-1695. PMID: 20046044

41. Zhang G, Cowled C, Shi Z, Huang Z, Bishop-Lilly KA, et al. (2013) Comparative analysis of bat genomes provides insight into the evolution of flight and immunity. Science 339: 456-460. doi: 10. 1126/science.1230835 PMID: 23258410

42. Fites JS, Ramsey JP, Holden WM, Collier SP, Sutherland DM, et al. (2013) The invasive chytrid fungus of amphibians paralyzes lymphocyte responses. Science 342: 366-369. doi: 10.1126/science. 1243316 PMID: 24136969

43. Bouma HR, Carey HV, Kroese FG. (2010a) Hibernation: the immune system at rest? J Leukoc Biol 88: 619-624.

44. Bouma HR, Henning RH, Kroese FG, Carey HV. (2012) Hibernation is associated with depression of T-cell independent humoral immune responses in the 13-lined ground squirrel. Dev Comp Immunol.

45. Bouma HR, Strijkstra AM, Boerema AS, Deelman LE, Epema AH, et al. (2010b) Blood cell dynamics during hibernation in the European Ground Squirrel. Vet Immunol Immunopathol 136: 319-323.

46. Kurtz CC, Carey HV. (2007) Seasonal changes in the intestinal immune system of hibernating ground squirrels. Dev Comp Immunol 31: 415-428. PMID: 16930701 
47. Maniero GD. (2002) Classical pathway serum complement activity throughout various stages of the annual cycle of a mammalian hibernator, the golden-mantled ground squirrel, Spermophilus lateralis. Dev Comp Immunol 26: 563-574. PMID: 12031416

48. Maniero GD. (2005) Ground squirrel splenic macrophages bind lipopolysaccharide over a wide range of temperatures at all phases of their annual hibernation cycle. Comp Immunol Microbiol Infect Dis 28: 297-309. PMID: 16182368

49. Jaroslow BN, Serrell BA. (1972) Differential sensitivity to hibernation of early and late events in development of the immune response. J Exp Zool 181: 111-116. PMID: 4556623

50. Larsen B. (1971) Antibody formation in hedgehogs. II. Hibernating animals. Comp Biochem Physiol A Comp Physiol 38: 571-580. PMID: 4396827

51. Manasek FJ, Adelstein SJ, Lyman CP. (1965) The effects of hibernation on the in vitro synthesis of DNA by hamster lymphoid tissue. J Cell Physiol 65: 319-324. PMID: 5891143

52. Cahill JE, Lewert RM, Jaroslow BN. (1967) Effect of hibernation on course of infection and immune response in Citellus tridecemlineatus infected with Nippostrongylus brasiliensis. J Parasitol 53: 110 115. PMID: 6017221

53. Sieckmann DG, Jaffe H, Golech S, Cai D, Hallenbeck JM, et al. (2014) Anti-lymphoproliferative activity of alpha-2-macroglobulin in the plasma of hibernating 13-lined ground squirrels and woodchucks. Vet Immunol Immunopathol 161: 1-11. doi: 10.1016/j.vetimm.2014.05.006 PMID: 25113962

54. Maniero GD. (2000) The influence of temperature and season on mitogen-induced proliferation of ground squirrel lymphocytes. In: Heldmaier G, Klingenspor M, editors. Life in the Cold. New York: Springer. pp. 493-503.

55. Hampton M, Melvin RG, Kendall AH, Kirkpatrick BR, Peterson N, et al. (2011) Deep sequencing the transcriptome reveals seasonal adaptive mechanisms in a hibernating mammal. Plos One 6: e27021. doi: 10.1371/journal.pone.0027021 PMID: 22046435

56. Hampton M, Melvin RG, Andrews MT. (2013) Transcriptomic analysis of brown adipose tissue across the physiological extremes of natural hibernation. PloS One 8: e85157. doi: 10.1371/journal.pone. 0085157 PMID: 24386461

57. Yan J, Burman A, Nichols C, Alila L, Showe LC, et al. (2006) Detection of differential gene expression in brown adipose tissue of hibernating arctic ground squirrels with mouse microarrays. Physiol Genomics 25: 346-353. PMID: 16464973

58. Schwartz C, Hampton M, Andrews MT. (2013) Seasonal and regional differences in gene expression in the brain of a hibernating mammal. PloS One 8: e58427. doi: 10.1371/journal.pone.0058427 PMID: 23526982

59. Williams DR, Epperson LE, Li W, Hughes MA, Taylor R, et al. (2005) Seasonally hibernating phenotype assessed through transcript screening. Physiol Genomics 24: 13-22. PMID: 16249311

60. Bouma HR, Kroese FG, Kok JW, Talaei F, Boerema AS, et al. (2011) Low body temperature governs the decline of circulating lymphocytes during hibernation through sphingosine-1-phosphate. Proc Natl Acad Sci U S A 108: 2052-2057. doi: 10.1073/pnas.1008823108 PMID: 21245336

61. de Vrij EL, Vogelaar PC, Goris M, Houwertjes MC, Herwig A, et al. (2014) Platelet dynamics during natural and pharmacologically induced torpor and forced hypothermia. PloS One 9: e93218. doi: 10. 1371/journal.pone.0093218 PMID: 24722364

62. Melvin RG, Andrews MT. (2009) Torpor induction in mammals: recent discoveries fueling new ideas. Trends in Endocrinology \& Metabolism 20: 490-498.

63. Johnson JS, Reeder DM, Lilley TM, Czirják GÁ, Voigt CC, et al. (2015) Antibodies to Pseudogymnoascus destructans are not sufficient for protection against white-nose syndrome. Ecology and EvoIution 5: 2203-2214. doi: 10.1002/ece3.1502 PMID: 26078857

64. Muller LK, Lorch JM, Lindner DL, O'Connor M, Gargas A, et al. (2013) Bat white-nose syndrome: a real-time TaqMan polymerase chain reaction test targeting the intergenic spacer region of Geomyces destructans. Mycologia 105: 253-259. doi: 10.3852/12-242 PMID: 22962349

65. Schmieder R, Edwards R. (2011) Fast identification and removal of sequence contamination from genomic and metagenomic datasets. PloS One 6: e17288. doi: 10.1371/journal.pone.0017288 PMID: 21408061

66. Simao FA, Waterhouse RM, loannidis P, Kriventseva EV, Zdobnov EM. (2015) BUSCO: assessing genome assembly and annotation completeness with single-copy orthologs. Bioinformatics.

67. Love MI, Huber W, Anders S. (2014) Moderated estimation of fold change and dispersion for RNAseq data with DESeq2. Genome Biol 15: 550. PMID: 25516281

68. Leng N, Dawson JA, Thomson JA, Ruotti V, Rissman Al, et al. (2013) EBSeq: an empirical Bayes hierarchical model for inference in RNA-seq experiments. Bioinformatics 29: 1035-1043. doi: 10.1093/ bioinformatics/btt087 PMID: 23428641 
69. Suzuki R, Shimodaira H. (2006) Pvclust: an R package for assessing the uncertainty in hierarchical clustering. Bioinformatics 22: 1540-1542. PMID: 16595560

70. Eden E, Navon R, Steinfeld I, Lipson D, Yakhini Z. (2009) GOrilla: a tool for discovery and visualization of enriched GO terms in ranked gene lists. BMC Bioinformatics 10: 48. doi: 10.1186/1471-210510-48 PMID: 19192299

71. Supek F, Bošnjak M, Škunca N, Šmuc T. (2011) REVIGO summarizes and visualizes long lists of gene ontology terms. PloS One 6: e21800. doi: 10.1371/journal.pone.0021800 PMID: 21789182

72. Westermann AJ, Gorski SA, Vogel J. (2012) Dual RNA-seq of pathogen and host. Nature Reviews Microbiology 10: 618-630. doi: 10.1038/nrmicro2852 PMID: 22890146

73. Pannkuk EL, Risch TS, Savary BJ. (2015) Isolation and identification of an extracellular subtilisin-like serine protease secreted by the bat pathogen Pseudogymnoascus destructans. PLoS One 10: e0120508. doi: 10.1371/journal.pone.0120508 PMID: 25785714

74. O'Donoghue AJ, Knudsen GM, Beekman C, Perry JA, Johnson AD, et al. (2015) Destructin-1 is a collagen-degrading endopeptidase secreted by Pseudogymnoascus destructans, the causative agent of white-nose syndrome. Proc Natl Acad Sci U S A 112: 7478-7483. doi: 10.1073/pnas.1507082112 PMID: 25944934

75. Smyth C, Schlesinger S, Overton B, Butchkoski C. (2013) The alternative host hypothesis and potential virulence genes in Geomyces destructans. Bat Res News 54: 17-24.

76. Whittington A, Gow NA, Hube B. (2014) From commensal to pathogen: Candida albicans. In: Anonymous Human Fungal Pathogens.: Springer. pp. 3-18.

77. Casadevall A, Steenbergen JN, Nosanchuk JD. (2003) 'Ready made'virulence and 'dual use'virulence factors in pathogenic environmental fungi-the Cryptococcus neoformans paradigm. Curr Opin Microbiol 6: 332-337. PMID: 12941400

78. Swidergall M, Ernst JF. (2014) Interplay between Candida albicans and the antimicrobial peptide armory. Eukaryot Cell 13: 950-957. doi: 10.1128/EC.00093-14 PMID: 24951441

79. Hoyt JR, Cheng TL, Langwig KE, Hee MM, Frick WF, et al. (2015) Bacteria isolated from bats inhibit the growth of Pseudogymnoascus destructans, the causative agent of white-nose syndrome. PLoS ONE 10: e0121329. doi: 10.1371/journal.pone.0121329 PMID: 25853558

80. Rizzetto L, Kuka M, De Filippo C, Cambi A, Netea MG, et al. (2010) Differential IL-17 production and mannan recognition contribute to fungal pathogenicity and commensalism. J Immunol 184: 42584268. doi: 10.4049/jimmunol.0902972 PMID: 20228201

81. Reid DM, Gow NA, Brown GD. (2009) Pattern recognition: recent insights from Dectin-1. Curr Opin Immunol 21: 30-37. doi: 10.1016/j.coi.2009.01.003 PMID: 19223162

82. Yamasaki S, Matsumoto M, Takeuchi O, Matsuzawa T, Ishikawa E, et al. (2009) C-type lectin Mincle is an activating receptor for pathogenic fungus, Malassezia. Proc Natl Acad Sci U S A 106: 18971902. doi: 10.1073/pnas.0805177106 PMID: 19171887

83. Zhu L, Zhao X, Jiang C, You Y, Chen X, et al. (2013) C-type lectin receptors Dectin-3 and Dectin-2 form a heterodimeric pattern-recognition receptor for host defense against fungal infection. Immunity 39: 324-334. doi: 10.1016/j.immuni.2013.05.017 PMID: 23911656

84. Bernard F, Morel F, Camus M, Pedretti N, Barrault C, et al. (2012) Keratinocytes under fire of proinflammatory cytokines: bona fide innate immune cells involved in the physiopathology of chronic atopic dermatitis and psoriasis. J Allergy 2012.

85. Kunz S, Wolk K, Witte E, Witte K, Doecke W, et al. (2006) Interleukin (IL)-19, IL-20 and IL-24 are produced by and act on keratinocytes and are distinct from classical ILs. Exp Dermatol 15: 991-1004. PMID: 17083366

86. Werner S, Krieg T, Smola H. (2007) Keratinocyte-fibroblast interactions in wound healing. J Invest Dermatol 127: 998-1008. PMID: 17435785

87. Ramirez-Carrozzi V, Sambandam A, Luis E, Lin Z, Jeet S, et al. (2011) IL-17C regulates the innate immune function of epithelial cells in an autocrine manner. Nat Immunol 12: 1159-1166. doi: 10. 1038/ni.2156 PMID: 21993848

88. Taylor PR, Roy S, Leal SM Jr, Sun Y, Howell SJ, et al. (2014) Activation of neutrophils by autocrine IL17A-IL-17RC interactions during fungal infection is regulated by IL-6, IL-23, ROR [gamma] t and dectin-2. Nat Immunol 15: 143-151. doi: 10.1038/ni.2797 PMID: 24362892

89. Heath WR, Carbone FR. (2013) The skin-resident and migratory immune system in steady state and memory: innate lymphocytes, dendritic cells and T cells. Nat Immunol 14: 978-985. doi: 10.1038/ni. 2680 PMID: 24048119

90. Palmer JM, Kubatova A, Novakova A, Minnis AM, Kolarik M, et al. (2014) Molecular characterization of a heterothallic mating system in Pseudogymnoascus destructans, the fungus causing white-nose syndrome of bats. G3 (Bethesda) 4: 1755-1763. 
91. Harden LM, du Plessis I, Poole S, Laburn HP. (2008) Interleukin (IL)-6 and IL-1 $\beta$ act synergistically within the brain to induce sickness behavior and fever in rats. Brain Behav Immun 22: 838-849. doi: 10.1016/j.bbi.2007.12.006 PMID: 18255258

92. Moalem G, Tracey DJ. (2006) Immune and inflammatory mechanisms in neuropathic pain. Brain Res Rev 51: 240-264. PMID: 16388853

93. Couture R, Harrisson M, Vianna RM, Cloutier F. (2001) Kinin receptors in pain and inflammation. Eur J Pharmacol 429: 161-176. PMID: 11698039

94. Brownlee-Bouboulis SA, Reeder DM. (2013) White-nose syndrome-affected little brown myotis (Myotis lucifugus) increase grooming and other active behaviors during arousals from hibernation. J Wildl Dis 49: 850-859. doi: 10.7589/2012-10-242 PMID: 24502712

95. Wilcox A, Warnecke L, Turner JM, McGuire LP, Jameson JW, et al. (2014) Behaviour of hibernating little brown bats experimentally inoculated with the pathogen that causes white-nose syndrome. Anim Behav 88: 157-164.

96. Tobin DM, Ramakrishnan L. (2013) TB: the Yin and Yang of lipid mediators. Current Opinion in Pharmacology 13: 641-645. doi: 10.1016/j.coph.2013.06.007 PMID: 23849093

97. Prendergast BJ, Freeman DA, Zucker I, Nelson RJ. (2002) Periodic arousal from hibernation is necessary for initiation of immune responses in ground squirrels. Am J Physiol Regul Integr Comp Physiol 282: R1054-62. PMID: 11893609

98. Plaisance EP, Lukasova M, Offermanns S, Zhang Y, Cao G, et al. (2009) Niacin stimulates adiponectin secretion through the GPR109A receptor. Am J Physiol Endocrinol Metab 296: E549-58. doi: 10. 1152/ajpendo.91004.2008 PMID: 19141678

99. Lei M, Dong D, Mu S, Pan Y, Zhang S. (2014) Comparison of brain transcriptome of the greater horseshoe bats (Rhinolophus ferrumequinum) in active and torpid episodes. PloS One 9: e107746. doi: 10. 1371/journal.pone.0107746 PMID: 25251558

100. Zhang Y, Pan Y, Yin Q, Yang T, Dong D, et al. (2014) Critical roles of mitochondria in brain activities of torpid Myotis ricketti bats revealed by a proteomic approach. Journal of Proteomics 105: 266-284. doi: 10.1016/j.jprot.2014.01.006 PMID: 24434588

101. Meteyer CU, Barber D, Mandl JN. (2012) Pathology in euthermic bats with white nose syndrome suggests a natural manifestation of immune reconstitution inflammatory syndrome. Virulence 3.

102. Vonhof MJ, Russell AL, Miller-Butterworth CM. (2015) Range-Wide Genetic Analysis of Little Brown Bat (Myotis lucifugus) Populations: Estimating the Risk of Spread of White-Nose Syndrome. PloS One 10: e0128713. doi: 10.1371/journal.pone.0128713 PMID: 26154307

103. Peig J, Green AJ. (2009) New perspectives for estimating body condition from mass/length data: the scaled mass index as an alternative method. Oikos 118: 1883-1891.

104. Bolger AM, Lohse M, Usadel B. (2014) Trimmomatic: a flexible trimmer for Illumina sequence data. Bioinformatics 30: 2114-2120. doi: 10.1093/bioinformatics/btu170 PMID: 24695404

105. Haas BJ, Papanicolaou A, Yassour M, Grabherr M, Blood PD, et al. (2013) De novo transcript sequence reconstruction from RNA-seq using the Trinity platform for reference generation and analysis. Nature Protocols 8: 1494-1512. doi: 10.1038/nprot.2013.084 PMID: 23845962

106. Langmead B, Trapnell C, Pop M, Salzberg SL. (2009) Ultrafast and memory-efficient alignment of short DNA sequences to the human genome. Genome Biol 10: R25. doi: 10.1186/gb-2009-10-3-r25 PMID: 19261174

107. Li B, Dewey CN. (2011) RSEM: accurate transcript quantification from RNA-Seq data with or without a reference genome. BMC Bioinformatics 12: 323-2105-12-323.

108. Benjamini $Y$, Hochberg $Y$. (1995) Controlling the false discovery rate: a practical and powerful approach to multiple testing. Journal of the Royal Statistical Society.Series B (Methodological): 289300.

109. McGinnis S, Madden TL. (2004) BLAST: at the core of a powerful and diverse set of sequence analysis tools. Nucleic Acids Res 32: W20-5. PMID: 15215342

110. Meyer F, Paarmann D, D'Souza M, Olson R, Glass EM, et al. (2008) The metagenomics RAST server -a public resource for the automatic phylogenetic and functional analysis of metagenomes. BMC Bioinformatics 9: 386-2105-9-386. 